NASA Technical Memorandum 100917

AIAA-88-3301

\title{
Boundary Layer Development as a Function of Chamber Pressure in the NASA Lewis 1030:1 Area Ratio Rocket Nozzle
}

Tamara A. Smith

Lewis Research Center

Cleveland, Ohio

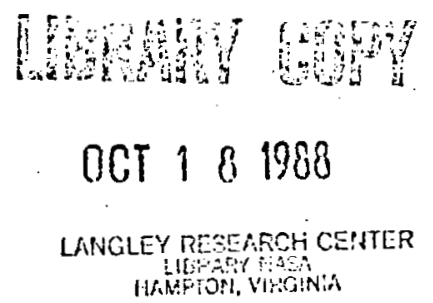

Prepared for the

24th Joint Propulsion Conference

cosponsored by the AIAA, ASEE, ASME, and SAE

Boston, Massachusetts, July 11-13, 1988 
BOUNDARY LAYER DEVELOPMENT AS A FUNCTION OF CHAMBER PRESSURE IN

\author{
THE NASA LEWIS 1030:1 AREA RATIO ROCKET NOZZLE \\ Tamara A. Smith \\ National Aeronautics and Space Administration \\ Lewis Research Center \\ Cleveland, Ohio 44135
}

\begin{abstract}
SUMMARY
Through the use of theoretical predictions of fluid properties, and experimental heat transfer and thrust measurements, the zones of laminar, transitional, and turbulent boundary-layer flow were defined for the NASA Lewis 1030:1 area ratio rocket nozzle. Tests were performed on the nozzle at chamber pressures from 350 to 1000 . psia. For these conditions the throat diameter Reynolds numbers varied from $3 \times 10^{5}$ to $10 \times 10^{5}$. The propellants used were gaseous hydrogen and gaseous.oxygen. Thrust measurements and nozzle outer-wall temperature measurements were taken during the 3-sec test runs.

Comparison of experimental heat transfer and thrust data with the corresponding predictions from the Two-Dimensional Kinetics (TDK) nozzle analysis program indicated laminar flow in the nozzle at a throat diameter Reynolds number of $3.2 \times 10^{5}$ or chamber pressure of $360 \mathrm{psia}$. Comparison of experimenta 1 and predicted heat transfer data indicated transitional flow up to and including a chamber pressure of 1000 psia. Predicted values of the axisymmetric acceleration parameter within the convergent and divergent nozzle were consistent with the above results. Based upon an extrapolation of the heat transfer data and predicted distributions of the axisymmetric acceleration parameter. transitional flow was predicted up to a throat diameter Reynolds number of $22 \times 10^{5}$ or 2600-psia chamber pressure. Above 2600-psia chamber pressure, fully developed turbulent flow was predicted.
\end{abstract}

\title{
INTRODUCTION
}

The objective of this study was to determine the rocket engine chamber pressure at which the boundary-layer flow in the NASA Lewis 1030:1 nozzle can be considered to be laminar, and at which pressure it will be turbulent. This information is needed in interpreting the measured thrust performance of the nozzle and to accurately predict its performance for specific test conditions. In 1986, the performance of a 1030:1 rocket nozzle at a chamber pressure of 350 psia was measured at the NASA Lewis Research Center (ref. 1). A subsequent study determined that the flow within the nozzle was laminar (ref. 2).. There is a need to determine the chamber pressure which will produce fully developed turbulent boundary-layer flow in the nozzle since turbulent flow produces more viscous drag than laminar flow and occurs in most high Reynolds number nozzle flows. Thus, the zones of laminar, transitional, and turbulent boundary-layer flow need to be defined for this nozzle as a function of Reynolds number or chamber pressure.

Tests were performed at chamber pressures from 350 to 1000 psia. These conditions correspond to throat diameter Reynolds numbers from $3 \times 10^{5}$ to $10 \times 10^{5}$. 
The propellants used were gaseous oxygen and gaseous hydrogen. Thrust measurements and nozzle outer-wall temperature measurements were taken during the 3-sec test runs. The hardware tested was an optimally-designed nozzle with a $25^{\circ}$ half angle of convergence, a $1-$ in. throat diameter, a contraction area ratio of $4.223: 1$ and an exit area ratio of $1030: 1$. The copper throat section was water-cooled and extended to an area ratio of $30: 1$. The nozzle skirt section was made of $0.25-i n$. carbon steel and was heat sink.

In this report, the experimental heat transfer and thrust measurements are first compared to those predicted for laminar and turbulent flow to determine the state of the boundary-layer development. Then, predicted flow conditions will be used in conjunction with results from previous relaminarization studies to estimate the boundary-layer development. The final conclusions will be based upon a combination of the experimental and predicted results.

SYMBOL LIST

A

$c^{*}$

$C_{f}$

$C_{p}$

F

H

K

$k$

P

$q^{\prime \prime}$

R

$r$

$\operatorname{Re}$

$\mathrm{T}$

$t$

u

$x$

$\alpha$

area

characteristic exhaust velocity

skin friction coefficient

specific heat at constant pressure

thrust

shape factor, displacement thickness/momentum thickness

acceleration parameter

conductivity

pressure

wall heat flux

local radius

radius

Reynolds number

temperature

time

velocity

axial distance from the throat

diffusivity 


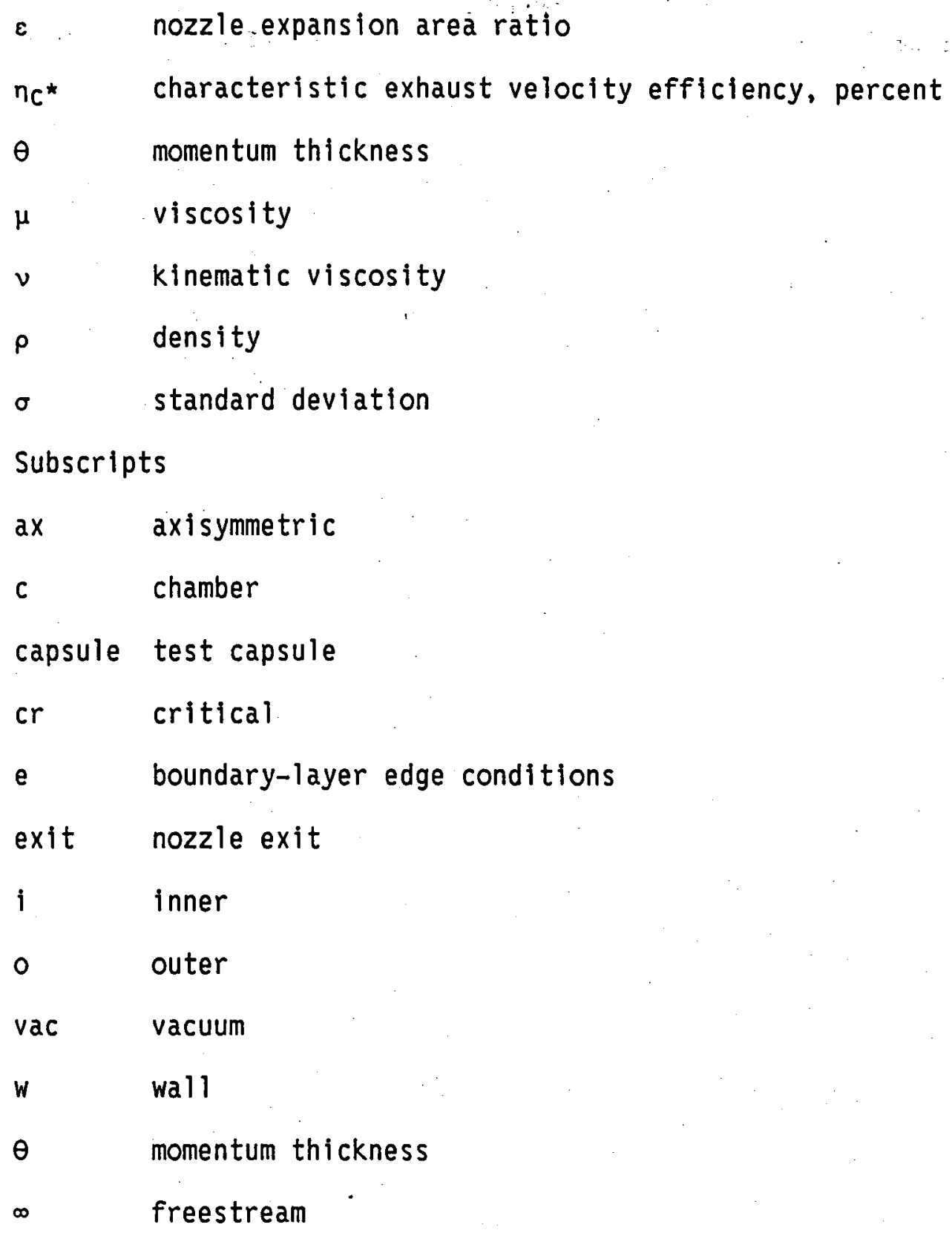

Figure 1 illustrates boundary-layer development as it is assumed to occur along the contour of a small rocket engine thrust chamber. The flow is assumed to be stagnant at the interface of the injector and combustor. From there, a laminar boundary layer develops which transitions to turbulent. This transition may or may not be completed depending upon the combustor length. If the transition is complete, the turbulent flow may be suppressed by the effects of acceleration (relaminarization). If there is complete suppression of turbulence, the boundary layer becomes laminar. As the flow continues through the nozzle, if the fluid properties produce a Reynolds number high enough to cause transition, it transitions to turbulent. 
Transition of a boundary layer from laminar to turbulent flow occurs as the Reynolds number increases. Determining the point at which transition begins depends upon the flow conditions and, even in this day of high technology, is still considered a "black art." The key to determining transition is to determine the stability of the boundary layer and, therefore, the conditions which cause stability or instability. Overall, accelerated flows ( $d p / d x<0$, favorable pressure gradient) like those which occur in a rocket nozzle, are considered more stable than decelerated flows $(\mathrm{dp} / \mathrm{dx}>0$, adverse pressure gradient) (ref. 3). Therefore, accelerated flows would tend to transition at a higher Reynolds number. Also, the transfer of heat from the fluid (gas) to the wall causes the limit of stability to be larger (ref. 3.). Therefore, based upon heat transfer, transition in a rocket nozzle would occur at a higher Reynolds number. Conversely, transition occurs at a lower Reynolds number on a rough wall than on a smooth wall. In general, the flow conditions in a smooth-walled rocket nozzle promote stability in the boundary layer.

Relaminarization is one of the names given to the phenomena whereby boundary-layer turbulence is suppressed by flow acceleration (favorable pressure gradient). To show the relationship between boundary-layer development and acceleration, let the acceleration parameter $K$ be defined as:

$$
K=\frac{v}{u_{\infty}^{2}} \frac{d u_{\infty}}{d x}
$$

Then, the momentum integral equation for turbulent plane flows with constant density and no suction or blowing can be written (ref. 4):

$$
\frac{d R e_{\theta}}{u_{\infty} d x / \nu}=\frac{C_{f}}{2}-K(1+H) R e_{\theta}
$$

If $K$ is positive, and if the term with $K$ in it is larger than the $C_{f}$ term, the turbulent boundary layer approaches an equilibrium or stable condition. The value of $\operatorname{Re}_{\theta}$ at the point of equilibrium depends on $K$. Where large values of $K$ lead to low values of $R_{\theta}$. Therefore, at some value of $K$, the equilibrium value of $\operatorname{Re}_{\theta}$ will be below the critical Reynolds number for transition at which point turbulence production ceases and a laminar boundary layer emerges. This value of $K$ is called critical $K$ or $K_{c r}$. For values of $K>K_{c r}$, the boundary layer is laminar. For values of $K<\mathrm{K} c r$ and above zero, there may be some suppression of turbulence which produces a transitional-type boundary-layer flow. In this report, the term "relaminarized flow" will refer to flow in which there is complete suppression of turbulence (laminar flow) and partial suppression of turbulence (transitional flow).

The effects of relaminarization in rocket nozzles were first noticed around the 1950's as a reduction in nozzle wall heat transfer. During this period, very large efforts in rocket engine research were beginning. Essential to these efforts was the measurement of combustion chamber and nozzle heat transfer rates, especially around the throat section where heat transfer rates are the highest. At that time, turbulent boundary-layer flow, which produces roughly twice as much heat transfer as laminar flow, was assumed. However, the measured heat fluxes were significantly lower than predicted in the throat section using this assumption. It was speculated that the reduction in heat transfer was due to the onset of reverse transition, or relaminarization 
of the boundary layer. At that point, no other experimental evidence was available to support this theory.. Therefore, several studies were conducted to explore this phenomena and its effects.

Moretti and Kays (ref. 5) measured heat transfer of low velocity air with accelerating turbulent flow along a flat plate with varying wall temperature and varying freestream velocity. In this study, they used the acceleration parameter. $K$ as a measure of the acceleration effect. The acceleration parameter is essentially the ratio of a geometric acceleration parameter to the local Reynolds number based on chamber diameter, and is usually defined as:

$$
K=\frac{v_{\infty}}{u_{\infty}^{2}} \frac{d u_{\infty}}{d x}
$$

Moretti and Kays found that at moderate values of $K$, there was a lower average turbulence intensity than found without flow acceleration. In fact, at values of $K$ greater than $3.3 \times 10^{-6}$, the heat transfer decreased sharply and approached the value for a purely laminar flow. At $K>3.5 \times 10^{-6}$, there was no further reduction in heat transfer. It is important to note that these results were for a heated wall where heat transfer occurred from the wall to the fluid.

Back, Cuffel and Massier (ref. 6) performed boundary-layer and heat transfer measurements for air flow through cooled, conical nozzles. Velocity and temperature profiles across the boundary layer were determined by measuring total pressure and total temperature. They found that at the higher chamber pressures, the heat transfer matched that of a turbulent flow. At lower pressures, they found a reduction in heat transfer along the convergent section. From their results, they estimated $K_{c r}$ as $2 \times 10^{-6}$ to $3 \times 10^{-6}$ where they defined K as:

$$
K=\frac{\mu_{e}}{\rho_{e} u_{e}^{2}} \frac{d u_{e}}{d x}
$$

The boundary-layer measurements showed a change in the velocity and temperature profile near the wall at large values of $K$. In fact, the profiles became laminar-like. With regard to rocket nozzle geometry, they found that there was a greater reduction in heat transfer in the throat section of a nozzle with a larger half angle of convergence, but the same contraction area ratio. Therefore, their results suggested that an increase in the convergent half angle increases the effect of acceleration.

They also noted that there was a lag in the thermal response to acceleration. Their conclusions were that acceleration affects the velocity distribution in a flow undergoing relaminarization more than it affects the temperature distribution. The implication, then, is that relaminarization effects occur at larger Reynolds numbers than would be indicated by the measured heat transfer. Thus, although the measured heat transfer may be characteristic of a turbulent boundary layer, acceleration may be affecting the friction coefficient and hence the drag may be less than for turbulent flow.

Schoenman (ref. 7) presented thermal data from four different thrust chambers with different propellants. The data from his tests and other small 
engine tests suggested that below a throat diameter Reynolds number of $2 \times 10^{5}$, all nozzles will have laminar boundary-layer flow. In the Reynolds number range between $2 \times 10^{5}$ and $4 \times 10^{5}$, the boundary-layer characteristics may be laminar, transitional, or turbulent depending upon the geometry, surface roughness, and the combustion effects.

One of the most significant studies was done by Nash-Webber (ref. 8). In this study, he flowed air over a flat plate and varied the imposed pressure gradient. In effect, he produced relaminarization in compressible, turbulent flow over an adiabatic wall in the ranges of Mach and Reynolds numbers typical of rocket nozzles. During these tests, wall shear stress was measured. From his results, he determined the coupled effects of acceleration and characteristic Reynolds number. It should be noted that Nash-Webber varied from previous studies and used adiabatic wall conditions to define his acceleration parameter and momentum thickness Reynolds number as follows:

$$
K=\frac{\mu_{w}}{\rho_{w} u_{e}} \frac{d u_{e}}{d x} \text { and } \operatorname{Re}_{\theta}=\frac{\rho_{e} u_{e} \theta}{\mu_{w}}
$$

He presented his results in the form of a "laminarization map" which defined the regions of complete suppression of turbulence (laminar flow), partial suppression (transitional flow), and no suppression (turbulent flow) for boundarylayer flow over an adiabatic wall. The purpose of the map was to plot the predicted boundary-layer conditions along a given nozzle wall as a trajectory on this diagram. Entry of the trajectory into the region defined for relaminarization indicates the onset of laminarization for that device.

Another significant study (ref. 9) was done in which heat transfer and boundary-layer measurements were obtained for hot air flow through the convergent section of a cooled nozzle with a $30^{\circ}$ half angle of convergence. The study was performed over a range of chamber pressures corresponding to throat diameter Reynolds numbers of $6 \times 10^{5}$ to $50 \times 10^{5}$. Boldman found that the throat heat transfer at a throat diameter Reynolds numbers below about $10^{6}$ was equal to that predicted for a laminar boundary layer. He also found that at the lower chamber pressures, although the boundary-layer profile upstream of the convergent section indicated turbulent flow, a profile taken in the convergent section was altered suggesting transition towards a laminar-type boundary layer. Within this study, an axisymmetric acceleration parameter was derived from the integral momentum equation for axisymmetric flow. This parameter Kax was defined as

$$
K_{a x}=\frac{\nu_{\infty}}{u_{\infty}^{2}} \frac{d u_{\infty}}{d x}+0.352 \frac{\nu_{\infty}}{u_{\infty} r} \frac{d r}{d x}
$$

A critical value of $K_{a x}, K_{a x}$, was estimated using the criteria for flat plate boundary-layer transition and was found to be $2.88 \times 10^{-6}$. Boldman found that calculations of $K_{2 x}$ could be used to predict the depressions in heat transfer due to flow acceleration and relaminarization. However, it was noted that although $K_{a x}$ was less than $K_{a x_{c r}}$ at the throat for the lower chamber pressures, laminar heat flux was measured. Therefore, it appears that high values of $K_{a x}$ upstream affected the boundary layer downstream to the point of lowering $\mathrm{K}_{\mathrm{ax}}$. 
Following the above mentioned studies and several others, it was determined that for rocket nozzles relaminarization is controlled by the chamber contour and by the product of chamber pressure and thrust at the throat plane, since this product determines the throat diameter Reynolds number (ref. 10). Large convergence angles, large contraction ratios, and small throat radi $i$ of curvature promote relaminarization. It was also found that high values of $K$ upstream of the throat could lower $K_{\mathrm{cr}}$ near the throat.

A summary of results from several studies appears in reference 10 . A suggested upper limit for relaminarization is set at a value of chamber pressure times thrust less than $10^{5} 1 \mathrm{bf}^{2} / \mathrm{in} .^{2}$. Further, the transition zone, or throat diameter Reynolds number range where the relaminarization process is started but not completed, is estimated to extend from $2 \times 10^{5}$ to $17 \times 10^{5}$, depending on the convergence angle.

As mentioned previously, the significance of studies on boundary-layer development and relaminarization is to enable rocket engine designers to predict heat transfer in the combustion chamber and throat section. This information is necessary to design engine cooling systems. Currently, the concept of a high performance, compact (high chamber pressure) space engine is being evaluated. This concept includes the use of large area ratio nozzles. Because of the large area ratio, boundary-layer drag is a significant factor in evaluating the design for optimal performance. According to prediction, turbulent boundary-1ayer drag reduces the thrust performance for the NASA Lewis 1030:1 nozzle about 3.5 percent below the performance predicted for a completely laminar boundary layer (ref. 11). Therefore, it is important to understand the boundary-layer development in large nozzles such that the correct drag and, thus, correct performance can be predicted for specific run conditions.

Tests have been performed on a 1030:1 nozzle contour at a low chamber pressure which resulted in laminar flow as evidenced by the experimental nozzle wall heat transfer. Tests need to be done on the same nozzle at a pressure which produces fully developed turbulent flow. To do these tests, it is necessary to define the chamber pressure at which acceleration has no effect on the boundary layer in the nozzle. Not only will this help to define an experimental program, but it will also provide insight into the design of similar space engines.

\section{APPARATUS AND INSTRUMENTATION}

\section{Test Facility}

Testing was done in the altitude test capsule at the NASA Lewis Rocket Engine Test Facility (RETF). Figure 2 is an illustration of RETF with cutaway views of the test capsule and spray cooler. The operation of the facility was as follows: When the engine was fired, the exhaust gases flowed into the diffuser where the kinetic energy of the exhaust was used to accomplish some of the altitude pumping. From the diffuser, the exhaust gases flowed into the spray cooler, where approximately one-half of the exhaust was condensed to water and flowed out the vertical drain line. The other half was pumped by the gaseous nitrogen ejectors shown mounted on top of the spray cooler. The exhaust from these ejectors was directed up through two short stacks and vented to the atmosphere. 
The thrust stand used in this facility was capable of measuring $3000 \mathrm{lb}$. full scale and was attached to a foundation that was separate from the test capsule bulkhead. The thrust stand was designed to have a $2 \sigma$ (standard deviation) variation of less than +0.1 percent of full scale, and was calibrated against a load cell that had $\bar{a} 2 \sigma$ variation of less than \pm 0.05 percent of full scale.

\section{Test Hardware}

The NASA Lewis 1030:1 thrust chamber hardware consists of three components: the combustion chamber, throat section, and nozzle skirt. Figure 3 is a sketch of this hardware. As shown, the combustion chamber was $6.0 \mathrm{in}$. long and had an internal diameter of $2.055 \mathrm{in}$. This combustor was made of copper with 1.0-in.-thick walls and was uncooled or heat-sink hardware.

The throat section had a half angle of convergence of $25^{\circ}$ and a contraction ratio of 4.223 . The radius of curvature upstream was 1.0 in. and downstream was $0.2 \mathrm{in}$. The throat section converged to a $1.00 \mathrm{in}$. throat and then diverged to an area ratio of 29.9. For the 350-psia chamber pressure tests, the throat section was made of nickel with a ceramic coating on the inner wall and a water jacket around the throat that extended to an area ratio of approximately five. For all other tests, the throat section was made of copper with water coolant channels along the entire length of the section. This difference in hardware between the test cases should not affect the results. The 350-psia chamber pressure cases were found to have laminar flow in the nozzle and, therefore, the use of the water-cooled copper throat during these tests would not have altered the results.

The nozzle skirt section extended from an area ratio of 29.9 to 1030 . The axial length was approximately $4 \mathrm{ft}$ and the exit plane diameter was 32 in. This section was made of $0.25-i n$. thick carbon steel and was uncooled or heatsink hardware. The roughness measurement for the skirt was found to be 32 rms, which is in the regime of smooth surfaces.

The nozzle contour past the throat was designed using the Rao Nozzle Contour Program (ref. 12) and the Boundary Layer Integral Matrix Procedure (BLIMP-J) Program (ref. 13). The Rao program calculated the inviscid optimal nozzle contour for a GH2/G02 1000:1 nozzle with a 1-in. throat, a chamber pressure of $1000 \mathrm{psia}$, and a nozzle length equivalent to 100 percent of a $15^{\circ}$ cone. Using the Rao contour, the BLIMP-J program was run using GH2/GO2 propellants, a chamber pressure of $1000 \mathrm{psia}$, and a mixture ratio of six, to calculate the boundary-layer displacement thickness along the nozzle. The BLIMP-J program then added this thickness to the original Rao contour to produce the nozzle coordinates that were used to make the hardware.

Figure 4 is a photograph of the inside of the test capsule with the 1030:1 nozzle in the process of being installed.

\section{Instrumentation}

Nozzle outer-wall temperatures were measured by chromel-constantan and chromal-alumel thermocouples spot-welded to the nozzle surface. These thermocouples were referenced to a $150^{\circ} \mathrm{F}$ oven. A calibration point was taken on 
the thermocouples prior to testing. The results indicated all the thermocouples were within \pm 3 of accuracy. "Four thermocouples were equally spaced circumferentially at axial locations corresponding to area ratios of $50,100,200$, $300,388,500,635,800$, and 975 . Thermocouple outer wall measurements were not taken on the throat section since it was cooled hardware.

Pressure taps were placed in the nozzle wall at the same axial positions as the thermocouples. These static pressure measurements were used to affirm that the flow in the nozzle was fully expanded.

\section{ANALYSIS}

Fluid properties, nozzle-wall heat transfer, and thrust performance were predicted using version 2.4 (December 1984) of the Two-Dimensional Kinetics (TDK) nozzle analysis computer code (ref. 14). TDK calculates the twodimensional and kinetic effects on the performance of liquid propellant exhaust nozzles. The basic method of analysis used is the method of characteristics for kinetic expansions. A Boundary-Layer Module (BLM) has also been included in this program which takes the inviscid fluid properties predicted with the method of characteristics and calculates wall-heat flux and boundary-layer drag. Within BLM, the continuity, momentum, and energy equations for compressible boundary-layer flow in a symmetric nozzle are solved using a two-point finite difference method developed by Keller and Cebeci (ref. 15). The turbulence model used is the Cebeci-Smith eddy-viscosity formulation (ref. 16) which has been tested for many types of flows with various boundary conditions.

Hardware specifications and test conditions were used to write the input files to TDK so that this program would accurately model the nozzle performance. The experimental results used in the input files were: chamber pressure, mixture ratio, fuel injection temperature, oxidizer injection temperature and experimentally determined nozzle inner wall temperatures.

Boundary-layer edge conditions in the combustor were input to the program based upon estimated values since no data was taken in the combustor. Wall temperatures in the throat section were also input based upon estimated values. To determine the sensitivity of the estimated wall temperatures in the throat section on the predicted results, the TDK program was first run with the estimated wall temperatures. Then, it was run again with a 25 percent increase in the wall temperatures. It was run a third time with a 25 percent decrease in wall temperature under the original estimate. The results showed that the predicted acceleration parameter was not affected by the wall temperature, since it is calculated using only freestream properties. The predicted momentum thickness Reynolds number was affected by wall temperature to the extent that a 25 percent change in wall temperature produced a maximum change of 2.7 percent in the momentum thickness Reynolds number along the throat section. A 25 percent change in throat-wall temperature produced a 0.015 percent change in predicted thrust. Neither of these effects are significant for this study.

\section{DATA REDUCTION}

During each 3-sec test run, thrust measurements, nozzle wall static pressure, and nozzle outer-wall temperatures were taken. These measurements were taken at a rate of $50 / \mathrm{sec}$, averaged in groups of five, and displayed at $0.1 \mathrm{sec}$ 
intervals. The nozzle wall static pressure measurements indicated that the nozzle flow was fully expanded in about $2.5 \mathrm{sec}$. All the data presented in this report was collected immediately before the engine was shut down. All the data for the 350-psia chamber pressure tests are from references 1 and 2 .

Thrust was measured using a specially designed thrust stand which could measure $3000 \mathrm{lb}$. full scale and had a $2 \sigma$ variation of less than +0.1 percent of full scale. To account for a zero shift due to variations in ambient (capsule) pressure, a correction was added to the measured thrust as a function of the capsule pressure. Then, vacuum thrust was calculated as:

$$
F_{\text {vac }}=F+\left(P_{\text {capsule }} \cdot A_{\text {exit }}\right)
$$

As mentioned previously, nozzle outer-wall temperatures were measured at several axial locations. Heat flux and inner-wall temperatures at each thermocouple location were determined by solving the energy equation:

$$
\rho C_{p}\left(\frac{\partial T}{\partial t}\right)=\frac{1}{r} \frac{\partial}{\partial r}\left[(k r) \frac{\partial T}{\partial r}\right]
$$

Assuming constant properties, no axial or circumferential conduction, adiabatic outer-wall and a linear rate of temperature rise, the following equations were obtained:

$$
\begin{gathered}
T_{i}=T_{0}-\frac{R_{0}^{2}}{4 \alpha} \frac{\partial T}{\partial t}\left[1-\left(\frac{R_{i}}{R_{0}}\right)^{2}+\ln \left(\frac{R_{i}}{R_{0}}\right)^{2}\right] \\
q_{i}^{\prime \prime}=\frac{k R_{i}}{2 \alpha} \frac{\partial T}{\partial t}\left[\left(\frac{R_{0}}{R_{i}}\right)^{2}-1\right]
\end{gathered}
$$

Thus, inner-wall temperatures and heat flux to the wall were calculated using the measured outer-wall temperature $T_{0}$, the measured temperature rise rate $(\partial T / \partial t)$, and properties of the carbon steel wall.

As mentioned previously, four temperature measurements were taken at each axial location. For each of these measurements, a heat flux was calculated. These four values were then averaged to determine the heat flux at that axial location. Also, in order to account for the effect of combustion efficiency, the fluxes were adjusted in the following manner:

$$
q^{\prime \prime}=\frac{q^{\prime \prime}}{\left(n_{c^{*}}\right)^{2}}
$$

The term $\left(n_{c}\right)^{2}$ represents the adjustment for combustion efficiency based on the fact that $c^{*}$ is proportional to the square root of the total chamber temperature. 


\section{RESULTS}

The purpose of this study is to define the zones of laminar, transitional, and turbulent boundary-layer flow for the NASA Lewis 1030:1 rocket nozzle. These zones will be established in terms of the throat diameter Reynolds number, which is determined by the chamber pressure and throat size. The procedure used in this paper to determine the flow:zones is as follows: First, the rocket nozzle was tested at various chamber pressures while measuring thrust and nozzle outer wall temperature. Static pressure measurements were also taken and indicated fully expanded flow for the test runs discussed in this report. Then, the TDK program was run to match each test case assuming (1) laminar flow which transitions to turbulent in the combustor, and (2) completely laminar flow throughout. Next, the experimental wall heat flux was compared to the predicted fluxes for the two theoretical cases to infer the state of the boundary-layer development. Also, the thrust was compared to predictions to determine if the drag produced compared with that of a turbulent or laminar boundary layer. Lastly, predicted fluid properties were used in conjunction with results from previous relaminarization studies to estimate the state of the boundary layer.

\section{Heat Transfer}

Figures 5 to 9 are plots of the experimental and predicted wall heat fluxes along the nozzle skirt for similar mixture ratios and chamber pressures of $360,656,747,984$, and 1004 psia, respectively. As shown, at 360-psia chamber pressure, the measured fluxes fall on the plot of the TDK prediction for laminar flow. As the chamber pressure increases, the experimental fluxes approach the turbulent plot. These results infer that at a chamber pressure of $360 \mathrm{psia}$, the flow was laminar. As the chamber pressure increased, the flow became transitional. In figure 9, at a chamber pressure of $1004 \mathrm{psia}$, the experimental fluxes fall about one-half way between the turbulent and laminar plots until near the end of the nozzle where the fluxes approach the turbulent plot. This infers that the flow was still transitional, but was almost fully developed turbulent flow when it reached the exit plane.

As a cross-check, figures 10 to 13 were made. The symbols represent the experimental heat fluxes for similar mixture ratio tests and chamber pressures of $354,360,656,747,984$, and $1004 \mathrm{psia}$. Each figure was plotted for one area ratio or axial location along the divergent nozzle. The dashed line represents the best fit to the data.

In figures 10 to 13 , a power curve fit was applied to the data over the range of chamber pressures from the 350 to $1004 \mathrm{psia}$ and the following results were obtained:

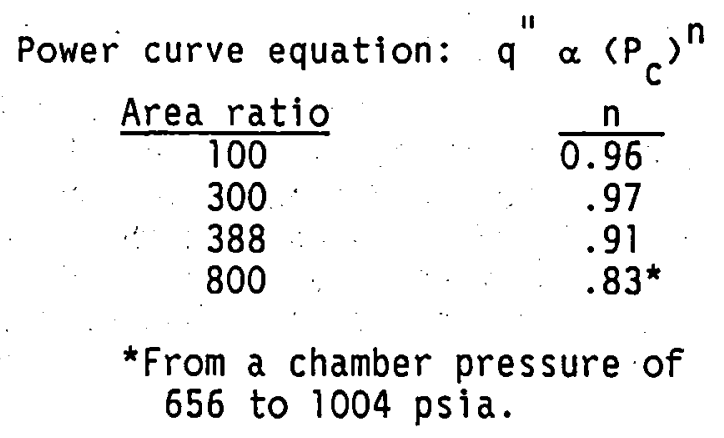


For external flows over a flat plate; the heat flux from a laminar boundary layer is proportional to the Reynolds number to the 0.5 power. This means that laminar boundary-layer heat flux should vary as a function of the square root of the chamber pressure. Similarly, for turbulent flow over a flat plate, the heat flux is proportional to the Reynolds number, or chamber pressure, to the 0.8 power. As shown, at an area ratio of 100 and 300 , the heat flux varies almost linearly (exponent is approximately 1) with the chamber pressure. This indicates that over this chamber pressure range, the heat flux increased at a greater rate than expected with laminar or turbulent flow. This is the trend or slope one would expect to see with flow that is transitioning from laminar to turbulent. As the area ratio increases to 388 , the exponent of the chamber pressure decreases indicating a decrease in slope of the data. However, the slope is still greater than that predicted for turbulent flow. At an area ratio of 800 , the slope of the data between a chamber pressure of 656 and $1004 \mathrm{psia}$ is closed to that predicted for fully developed turbulent flow. This indicates that at the higher chamber pressures, as the flow approached the exit plane, it was almost fully developed turbulent flow. These results are consistent to those presented in figures 5 to 9 .

\section{Thrust}

Figure 14 is a plot of the measured and predicted vacuum thrust for similar mixture ratios. The upper line represents the predicted vacuum thrust for completely laminar boundary-layer flow. The lower line represents the predicted vacuum thrust for boundary-layer flow that transitions to turbulent within the combustor. The symbols are thrust measurements taken at various chamber pressures. The uncertainty of the thrust measurements was calculated to be 1.12 percent (ref. 17). The predicted difference in vacuum thrust between laminar and turbulent flow is 2.9 percent.

As shown, all the experimental data fall on or near the laminar prediction, indicating laminar flow. Based upon a one-to-one comparison of the data to the predictions, the following information is obtained. At a chamber pressure of 360 psia, the thrust measurements are 2.2 percent above the laminar prediction and 5.1 percent above the turbulent prediction. At a chamber pressure of $656 \mathrm{psia}$, the thrust measurement is 0.3 percent above the laminar prediction and 3 percent above the turbulent prediction. At a chamber pressure of $747 \mathrm{psia}$, the thrust measurement is 0.7 percent above the laminar prediction and 3.6 percent above the turbulent prediction. Thus, as the chamber pressure increases from 360 to 656 and $747 \mathrm{psia}$, the thrust measurements are lower relative to the laminar and turbulent predictions. These results indicate an increase in drag relative to the assumed laminar flow found at 360 psia. This suggests the onset of transitional flow above 360-psia chamber pressure.

\section{Extrapolation of Experimental and Predicted Results}

Based upon the heat flux and thrust results, fully developed turbulent flow was not reached during the experiment. Therefore, the end of the transition zone must be predicted based upon an extrapolation of the experimental data and predictions of flow conditions at higher chamber pressures. Figure 15 is a plot of the heat flux obtained at an area ratio of 100 for similar mixture ratios. This point on the nozzle is about 7 in. downstream of the throat. The flux at an area ratio of 100 was chosen because it is the closest measurement 
near the throat which is not affected by the water-cooled throat hardware. The heat flux is presented as a function of throat diameter Reynolds number. The upper curve represents the predicted flux for a turbulent boundary layer. The zone around the turbulent curve represents the approximate accuracy of the prediction ( \pm 20 percent). The lower curve represents the predicted heat flux for a laminar boundary layer. The experimental fluxes are represented by symbols with a least squares curve fit applied to the data. As shown, an extrapolation of the curve fit intersects the turbulent plot at a throat diameter Reynolds number of about $22 \times 10^{5}$ which corresponds to a chamber pressure of 2600 psia. Based upon the accuracy of the turbulent flux prediction, this value is probably accurate to within 500 or 600 psia.

In order to predict the upper limit of the transition zone, the flow conditions obtained from the TDK program were used along with the calculated inner-wall temperatures to predict the boundary-layer development based upon the Nash-Webber laminarization map. The Nash-Webber map was chosen for comparison because it defines the boundaries for laminar, transitional, and turbulent flow based upon the effect of acceleration. The values of $K$ and $\operatorname{Re}_{\theta}$ were calculated as defined by Nash-Webber for the 747-psia chamber pressure case. The distribution of $K$ and $\operatorname{Re}_{\theta}$ on the Nash-Webber map indicated that the flow was expected to be entirely turbulent. However, this result is not supported by the heat flux and thrust data. In a previous study, Praharaj (ref. 18) also found that the Nash-Webber criteria predicted turbulence when the measured data indicated relaminarization. The problem appears to be that Nash-Webber's study was based upon an adiabatic wall with his $K$ parameter incorporating conditions at the wall. As mentioned previously, heat flux from the fluid to the wall causes the boundary layer to be more stable than heat flux from the wall to the fluid. Therefore, for a cooled wall or heat-sink hardware, the Nash-Webber laminarization limits would have to be lowered. Because the 1030:1 nozzle is heat-sink hardware, Nash-Webber's criteria cannot be applied.

Next, the predicted flow conditions were used to estimate the boundarylayer development based upon Boldman's results. Boldman's study was chosen because it was for axisymmetric flow through a cooled nozzle with a convergence half angle of $30^{\circ}$. These conditions are similar to those for the NASA Lewis 1030:1 nozzle. The acceleration parameter was calculated as specified in Boldman's paper (ref. 9). Local values of $K_{a x}$ for the nozzle are plotted in figures 16 to 20 as a function of the axial distance from the throat.

The critical value of $K_{a x}$ used by Boldman was $2.88 \times 10^{-6}$ and was based upon the assumption that laminarization occurs at a critical momentum thickness Reynolds number of 360 , which is the classical value for transition on flat plate. Later, Cebeci and Smith suggested that for compressible flow with a pressure gradient (as found with nozzle flow), the criteria for transition should be set at a $\operatorname{Re}_{\theta}$ of 400 (ref. 16). Therefore, the critical value of $\mathrm{K}_{a x}$ was recalculated using Boldman's derivation and a critical momentum thickness Reynolds number of 400 . The critical $K_{a x}$ then becomes $2.5 \times 10^{-6}$. This is the value which is indicated on figures 16 to 20 .

As shown, the value of $K_{a x}$ is quite high in the convergent part of the nozzle. However, as you cross the throat plane, the value drops. For each case, from a chamber pressure of $350 \mathrm{psia}$ up to $1000 \mathrm{psia}$, one would expect laminar flow in the convergent section based upon $K_{a x}>K_{a x_{c r}}$, and laminar flow in the throat section based upon the upstream influence of $K_{a x}$. This 
matches Boldman's prediction of laminar flow in the convergent section below a throat diameter Reynolds number of $10^{6}$. The affect of acceleration when $\mathrm{K}_{\mathrm{ax}}<\mathrm{K}_{\mathrm{ax}} \mathrm{cr}$ is predicted to decrease monotonically with the value of the acceleration parameter (ref. 8). Thus, in the divergent nozzle, one would expect less and less of an acceleration effect on the boundary-layer development as the flow expands to the exit. Therefore, one would expect the boundary layer to develop based upon the Reynolds number and the extent of suppression in the throat section. These predictions are consistent with the heat transfer results.

In order to predict the boundary-layer development at higher chamber pressures, figure 21 was drawn. Within this figure, the distribution of $K_{a x}$ and $\operatorname{Re}_{\theta}$ are shown along the nozzle for varlous chamber pressures. $K_{a x}$ and $\operatorname{Re}_{\Theta}$ have several variables in common. Yet, $K_{a x}$ contains only freestream variables with the only boundary-layer variable, $\theta$, contained in $\operatorname{Re}_{\theta}$. To understand the relaminarization phenomena, one must examine both these quantities. In NashWebber's study, $\operatorname{Re}_{\theta}$ is linked to $K$ by showing that as $\operatorname{Re}_{\theta}$ increases, $K_{c r}$ increases.

In figure 21, the momentum thickness Reynolds number was calculated using momentum thickness for a laminar boundary layer. Following each curve from left to right, the flow goes from the end of the combustor section to about 0.5 in. past the throat. A dashed curve is drawn to indicate the position of the throat. As one goes from the upper curve to the lower curve, chamber pressure equals $656,1004,1700,2100$, and $2600 \mathrm{psia}$. This range corresponds to throat diameter Reynolds numbers of $5.6 \times 10^{5}$ to $22 \times 10^{5}$.

Upon examining figure 21, one needs to bear in mind the approximate nature of these results. As mentioned previously, boundary-layer development depends on many factors such as the amount of acceleration, wall cooling, and roughness. The critical values of $K_{a x}$ and $R_{\theta}$, therefore, also depend upon these factors. Therefore, $K_{a x}$ cannot be used as an exact criteria, but, instead, as an indication of a trend or propensity towards a certain flow behavior.

For the three upper curves, in the convergent section, $K_{a x}$ is predicted to be quite high while $\mathrm{Re}_{\theta}$ is relatively low. Therefore, laminar or transitional flow seems likely. For the two lower curves (2100 and 2600 psia), in the convergent section $K_{a x}$ borders on the critical value and $R_{\theta} \theta$ has risen above its critical value. Thus, transitional or turbulent flow could exist. Therefore, in the convergent section, the transition zone may extend up to 2600 psia. For 211 of the curves, the acceleration parameter drops after the throat and the momentum thickness Reynolds number increases sharply. As the flow travels toward the exit, the acceleration parameter drops gradually and the momentum thickness Reynolds number remains at a fairly high value. Therefore, in the divergent nozzle, one would expect transitional or turbulent flow.

\section{CONCLUDING REMARKS}

Based upon the results of this analysis, the following recommendations are made. Because fully developed turbulent flow was not attained during this experiment, tests should be run on the nozzle at higher chamber pressures. Suggested run conditions are chamber pressures of 1500, 2000, 2500 and 3000 psia. Fully developed turbulent flow will be indicated as the chamber pressure at which thrust or wall heat flux matches the turbulent prediction, or 
the point at which thrust and wall heat flux remain at the same relative point between the laminar and turbulent prediction as chamber pressure increases.

The latter condition is chosen because the prediction program may not be able to predict turbulent performance as accurately as necessary. Fully developed turbulent flow will also be indicated (as in figures 10 to 13) by a heat flux profile with a slope that is proportional to the chamber pressure to the 0.8 power. Also, boundary-layer measurements should be taken to provide further data on the boundary-layer development.

As an alternative to running the nozzle at chamber pressures high enough to produce turbulent flow in the convergent section, an analysis could be done to estimate the acceleration effects and the transition location for a specific chamber pressure. Then, the TDK program would be run while altering the transition locations until the predicted heat flux distribution matches the experimental results. At that point, it would establish the amount of drag being produced which could be used in the nozzle performance database.

Other options to produce fully developed turbulent flow in the nozzle at lower chamber pressures include reducing the convergence angle or increasing the combustor length to produce a stronger turbulent boundary layer in the convergent section. Also, roughening the wall of the convergent section would produce more turbulence.

\section{SUMMARY OF RESULTS}

The objective of this study was to determine the rocket engine chamber pressures at which boundary-layer flow in the 1030:1 nozzle is laminar, transitional and fully developed turbulent flow. Tests were performed on the nozzle at chamber pressures from $350-1000 \mathrm{psia}$. These conditions correspond to throat diameter Reynolds numbers from $3 \times 10^{5}$ to $10 \times 10^{5}$. The propellants used were gaseous oxygen and gaseous hydrogen. Thrust measurements and nozzle outer wall temperature measurements were taken during the $3-\mathrm{sec}$ test runs. The hardware tested was a modified Rao contoured nozzle with a $25^{\circ}$ half angle of convergence, a 1 in. throat diameter, a contraction area ratio of 4.223 , and an exit area ratio of 1030 . The copper throat section was water-cooled and expanded to an area ratio of $30: 1$. The carbon steel nozzle skirt was heat-sink.

Results were based on a comparison of the experimental data and corresponding predictions from the Two-Dimensional Kinetics (TDK) nozzle analysis program. Predicted flow conditions were also used in conjunction with results from previous studies to estimate the state of the boundary layer at higher chamber pressures. The results are summarized as follows:

1. Comparison of experimental and predicted wall heat transfer in the nozzle skirt indicated completely laminar flow at chamber pressures around 360 psia, and transitional flow up to at least a chamber pressure of 1000 psia;

2. Comparison of experimental and predicted vacuum thrust indicated laminar flow at a chamber pressure of 360 psia and laminar or transitional flow up to at least 747-psia chamber pressure. Thrust measurements at 1000-psia chamber pressure were not available;

3. A least squares curve fit was applied to the wall heat flux data taken at an area ratio of 100 for various chamber pressures. Based upon an extrapolation of the curve, the transitional zone for the nozzle extends from a 
throat diameter Reynolds number of $3.2 \times 10^{5}$ to $22 \times 10^{5}$. This corresponds to a chamber pressure range of 360 to 2600 psia;

4. Nash-Webber's laminarization map, which is used to predict boundarylayer development, indicated turbulent flow at a chamber pressure of 747 psia. Comparison with the experimental results suggests Nash-Webber's criteria is not applicable to heat-sink or cooled hardware;

5. Using predicted flow conditions within the nozzle, distributions of the acceleration parameter $K_{a x}$ were calculated. These distributions indicated relaminarization effects in the convergent section which correlate with the heat transfer results found up to and including a chamber pressure of 1000 psia. Relaminarization effects in the convergent nozzle were predicted up to a chamber pressure in the range of 2100 to 2600 psia, or throat diameter Reynolds number of $17.6 \times 10^{5}$ to $22 \times 10^{5}$.

In conclusion, analysis of experimental data and predicted flow conditions indicates that for the NASA Lewis 1030:1 nozzle the laminar zone extends to a throat diameter Reynolds number of approximately $3.2 \times 10^{5}$. This corresponds to a chamber pressure of $360 \mathrm{psia}$. The transitional zone extends to a throat diameter Reynolds number of approximately $22 \times 10^{5}$, or a chamber pressure of 2600 psia. Above this point, fully developed turbulent flow is predicted. These results are consistent with previous studies.

\section{REFERENCES}

1. Pavli, A.J., Kacynski, K.J., and Smith, T.A., "Experimental Thrust Performance of a High-Area-Ratio Rocket Nozzle," NASA TP-2720, 1987.

2. Kacynski, K.J., Pavli, A.J., and Smith, T.A., "Experimental Evaluation of Heat Transfer on a 1030:1 Area Ratio Nozzle," NASA TP-2726, 1987.

3. Schlichting, H., Boundary-Layer Theory, McGraw-Hi11, New York, 1968.

4. Kays, W.M., and Crawford, M.E., Convective Heat and Mass Transfer, 2nd edition, McGraw-Hill, New York, 1980.

5. Moretti, P.M., and Kays, W.M., "Heat Transfer to a Turbulent Boundary Layer with Varying Free-Stream Velocity and Varying Surface Temperature -- An Experimental Study," International Journal of Heat and Mass Transfer, Vol. 8, Sept. 1965, pp. 1187-1202.

6. Back, L.H., Cuffel, R.F., and Massier, P.F., "Laminarization of a Turbulent Boundary Layer in Nozzle Flow -- Boundary. Layer and Heat Transfer Measurements with Wall Cooling," ASME Paper 69-HT-56, Aug. 1969.

7. Schoenman, L., and Block, P., "Laminar Boundary-Layer Heat Transfer in Low-Thrust Rocket Nozzles," Journal of Spacecraft and Rockets, Vol. 5, No. 9, Sept. 1968, pp. 1082-1089.

8. Nash-Webber, J.L., "Wall Shear-Stress and Laminarization in Accelerated Turbulent Compressible Boundary Layers," Report 94, Gas Turbine Laboratory, MIT, Apr. 1968. 
9. Boldman, D.R., Schmidt, J.F., and Gallagher, A.K., "Laminarization of a Turbulent Boundary Layer as Observed from Heat Transfer and Boundary Layer Measurements in Conical Nozzles," NASA TN D-4788, 1968.

10. "Liquid Rocket Engine Self-Cooled Combustion Chambers," NASA SP-8124, 1977.

11. Smith, T.A., Pavli, A.J., and Kacynski, K.J., "A Comparison of Theoretical and Experimental Thrust Performance of a 1030:1 Area Ratio Rocket Nozzle at a Chamber Pressure of $2413 \mathrm{kN} / \mathrm{m}^{2}$ (350 psia)," NASA TP-2725, 1987. (Also AIAA Paper 87-2069).

12. Nickerson, G.R., "The Rao Method Optimum Nozzle Contour Program," SEA Report 6/82/800.1, Software and Engineering Associates, Inc., Carson City, NV, June 1982 .

13. Evans, R.M., "Boundary Layer Integral Matrix Procedure - User's Manual," AEROTHERM-UM-75-64, Aerotherm Acurex Corp., Mountain View, CA, July 1975, NASA CR-144046.

14. Nickerson, G.R., Coats, D.E., and Dang, L.D., "Two-Dimensional Kinetic Reference Computer Program (TDK)," SN-63, Software and Engineering Associates, Carson City, NV, Apr. 1985, NASA CR-178628.

15. Keller, H.B., and Cebeci, T., "Accurate Numerical Methods for Boundary Layer Flows. II: Two-Dimensional Turbulent Flows," AIAA Journal, Vol. 10, No. 9, Sept. 1972, pp. 1193-1199:

16. Cebeci, T., and Smith, A.M.0., Analys is of Turbulent Boundary Layers, Academic Press, New York, 1974.

17. Davidian, K.J., Dieck, R.H., and Chuang, I., "A Detailed Description of the Uncertainty Analysis of High Area Ratio Rocket Nozzle Tests at the NASA Lewis Research Center," NASA TM-100203, 1987.

18. Praharaj, S.C., "Boundary Layer Simulator (BLIMPJ) Improvement," The 22nd JANNAF Combustion Meeting, Vol. 1, CPIA-PUBL-432, D.S. Eggleston, ed., Chemical Propulsion Information Agency, Johns Hopkins Univ., Laurel, MD, 1985, pp. 477-493. (Avai1. NTIS, AD-A165503). 


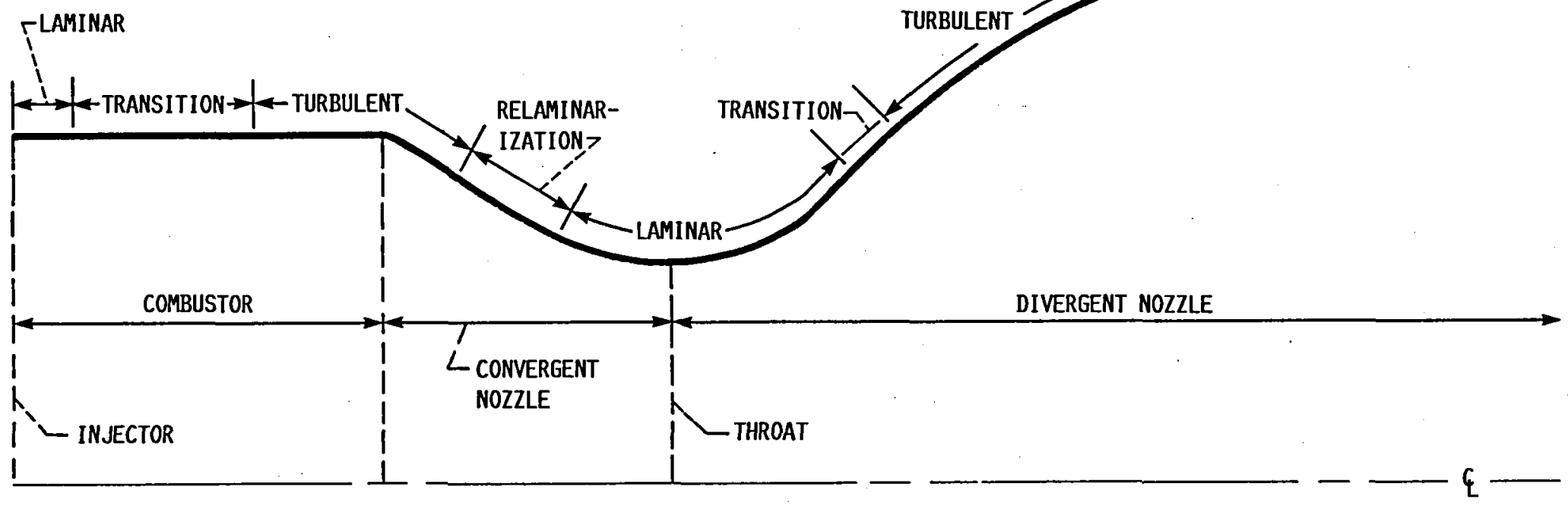

FIGURE 1. - BOUNDARY LAYER DEVELOPMENT IN SMALL THRUST CHAMBERS. 


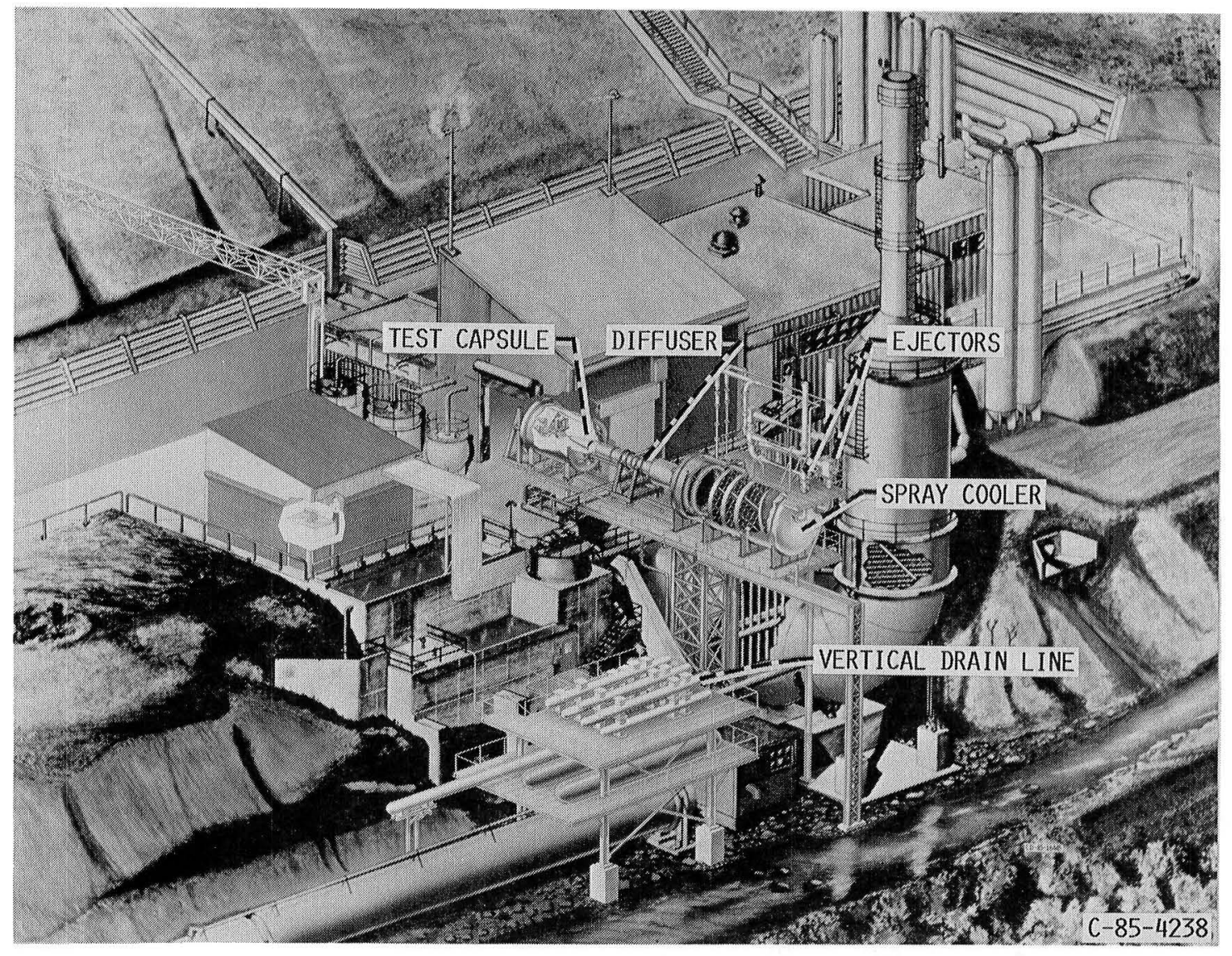

FIGURE 2. - ROCKET ENGINE TEST FACILITY (RETF) WITH CUTAWAY VIEWS OF THE TEST CAPSULE AND SPRAY COOLER.

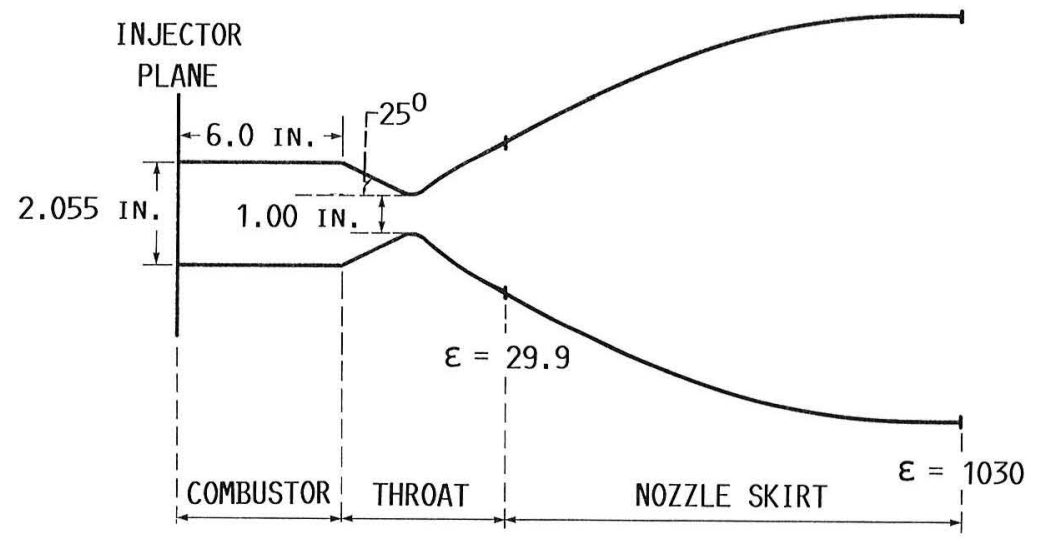

FIGURE 3. - DIMENSIONS OF TEST HARDWARE (NOT TO SCALE). 


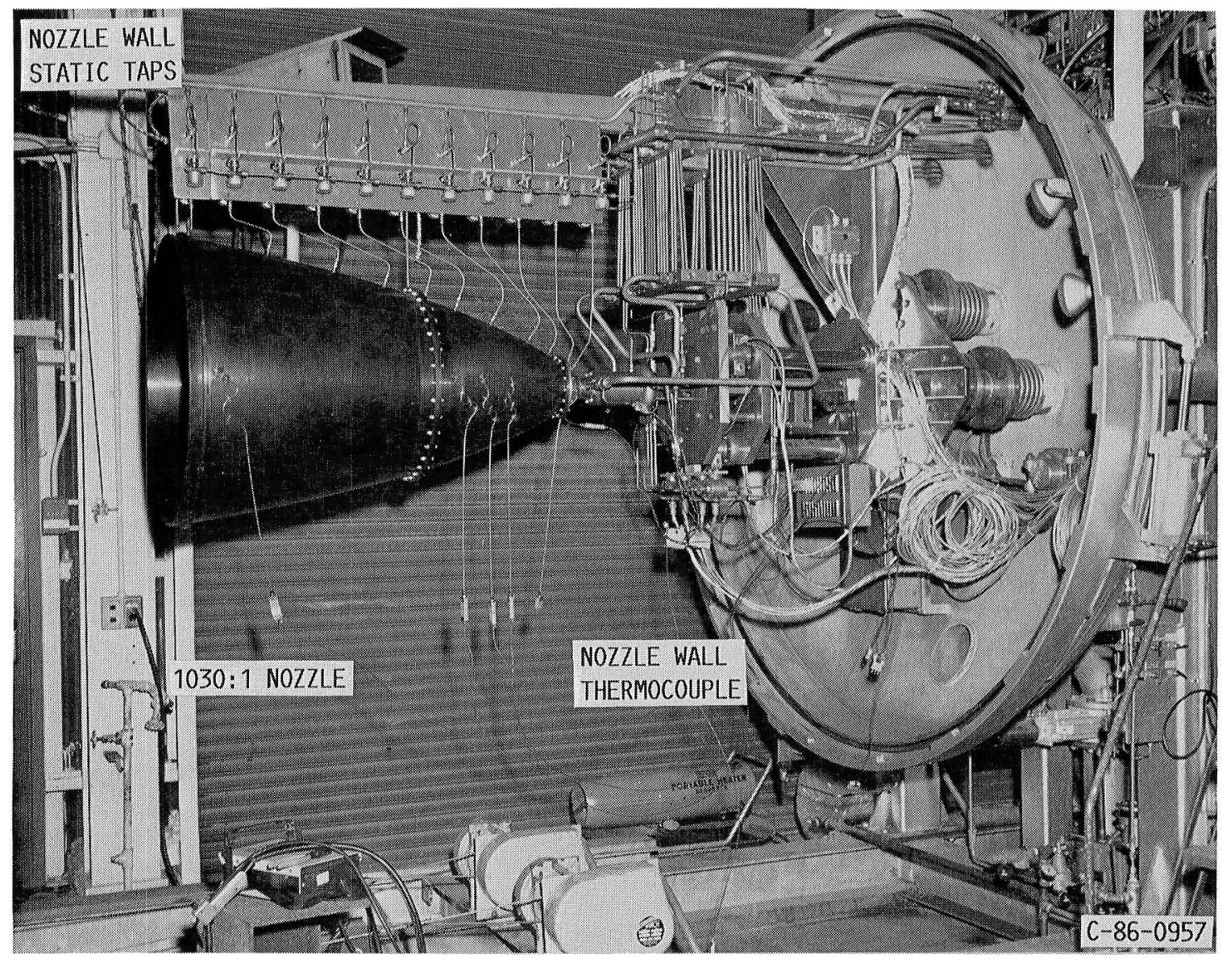

FiguRE 4. - ALTITUDE TEST CAPSULE - 1030:1 NOZZLE BEING INSTALLED IN THRUST STAND. 

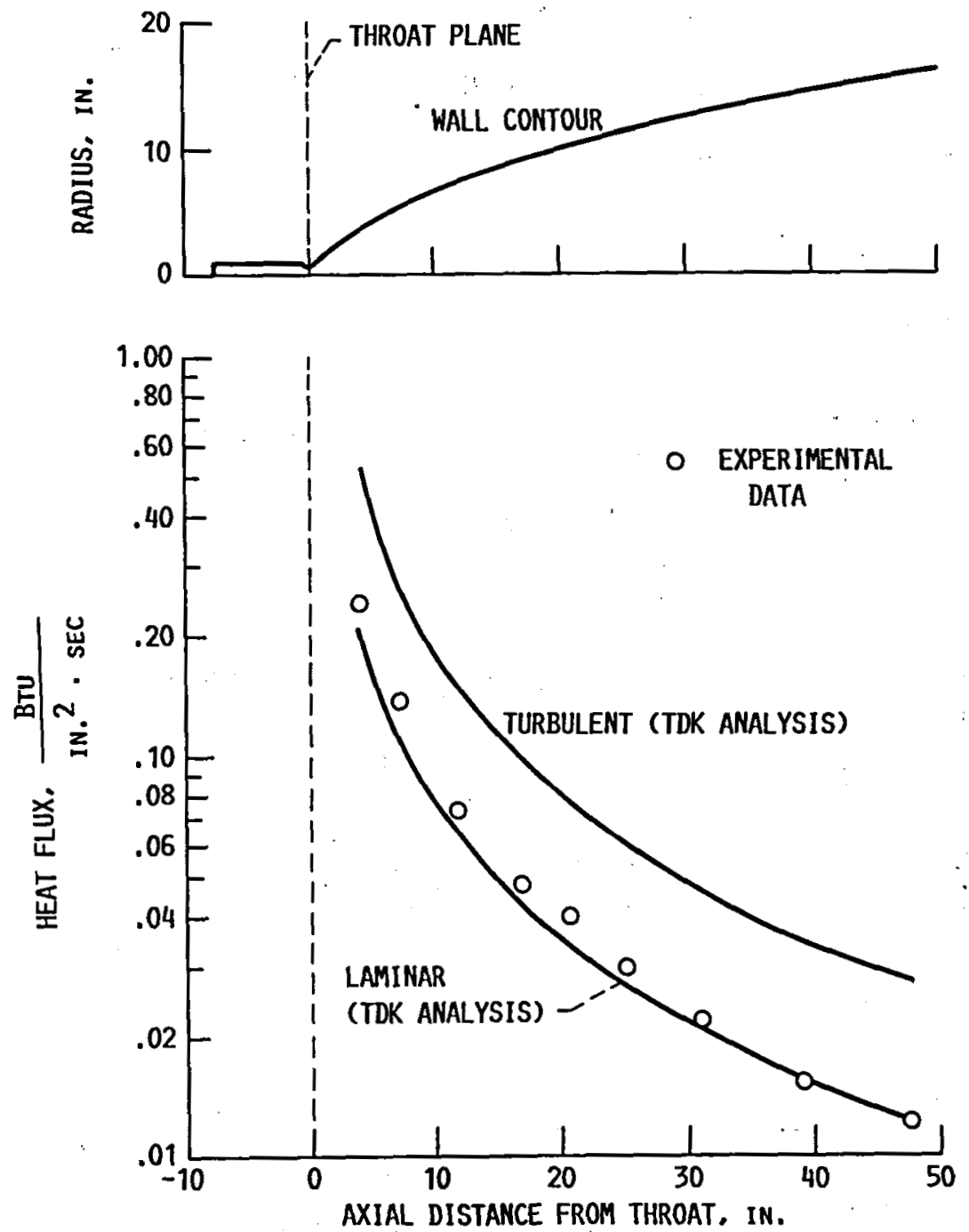

FIGURE 5. - EXPERIMENTAL AND PREDICTED WALL HEAT FLUX AT A CHAMBER PRESSURE OF 360 PSIA. 

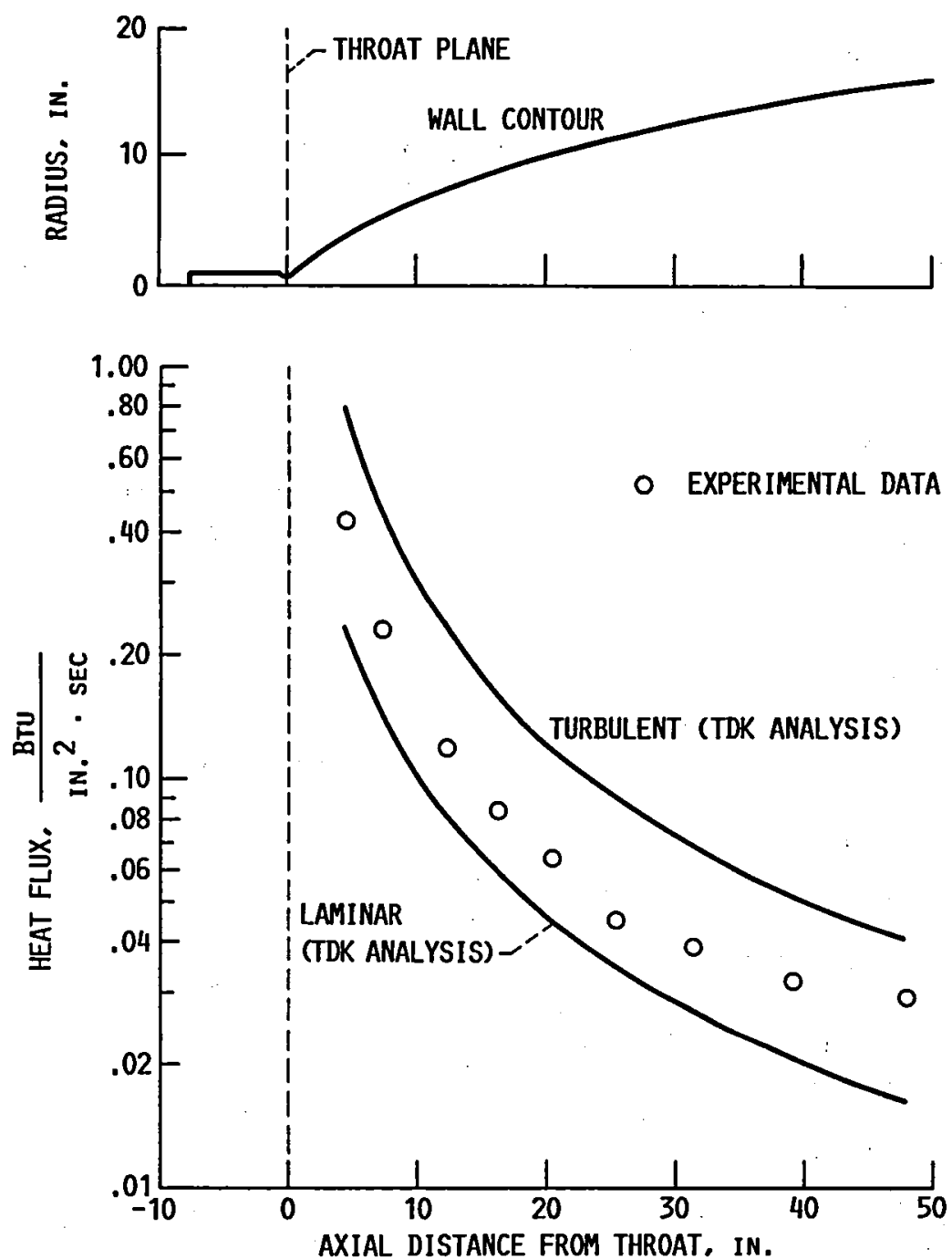

FIGURE 6. - EXPERIMENTAL AND PREDICTED WALL HEAT FLUX AT A CHAMBER PRESSURE OF 656 PSIA. 

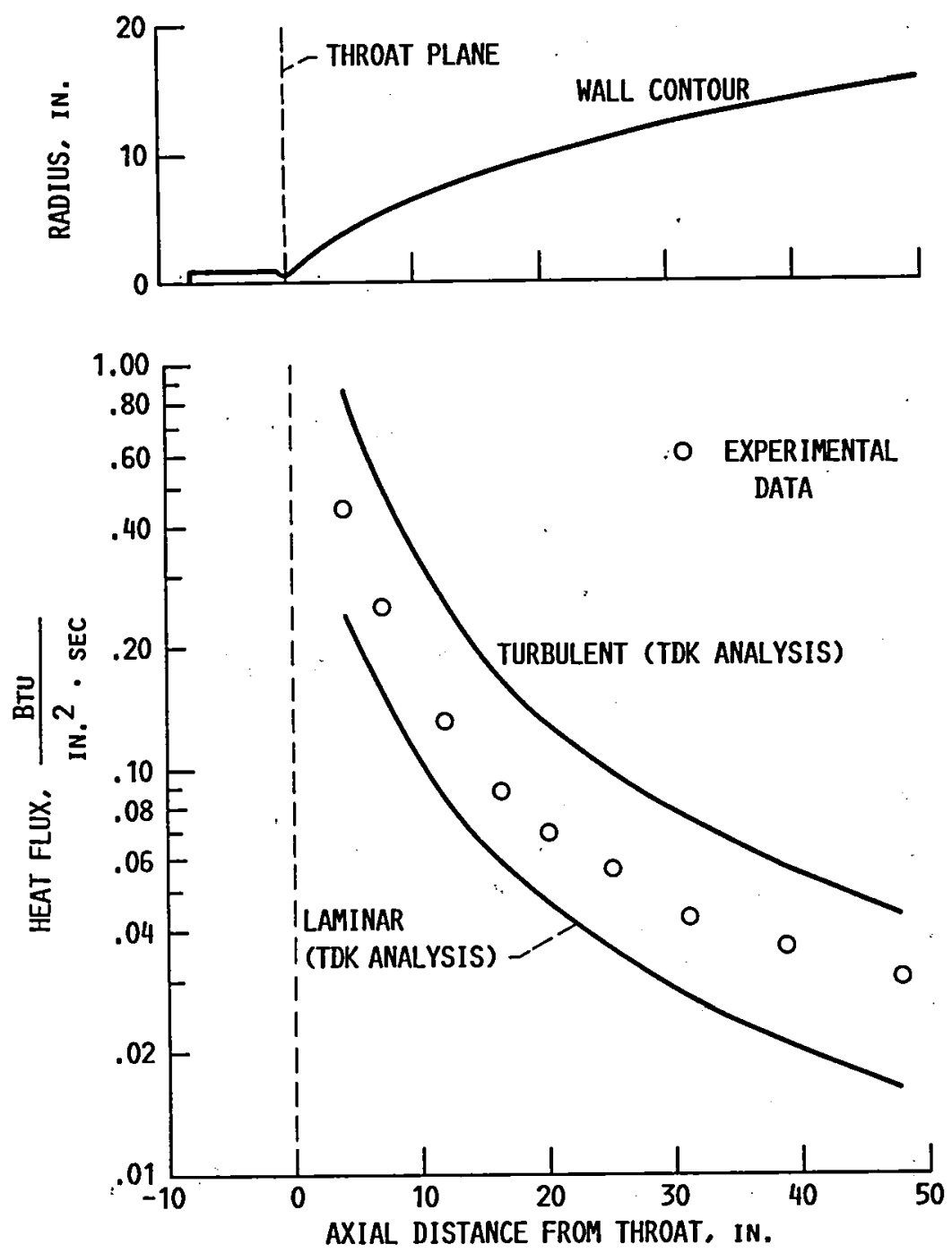

FIGURE 7. - EXPERIMENTAL AND PREDICTED WALL HEAT FLUX AT A CHAMBER PRESSURE OF 748 PSIA. 

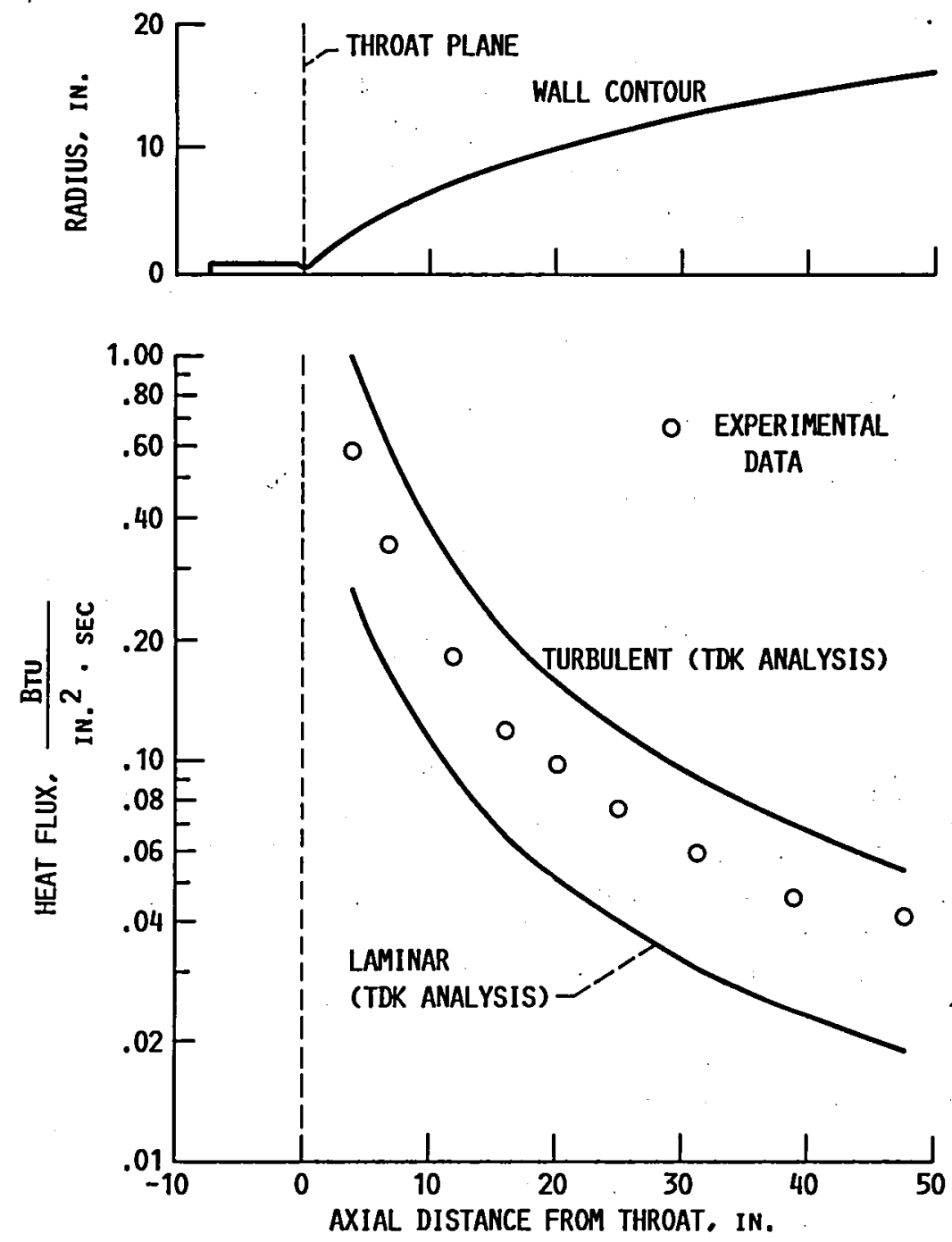

FIGURE 8. - EXPERIMENTAL AND PREDICTED WALL HEAT FLUX AT A CHAMBER PRESSURE OF 984 PSIA. 

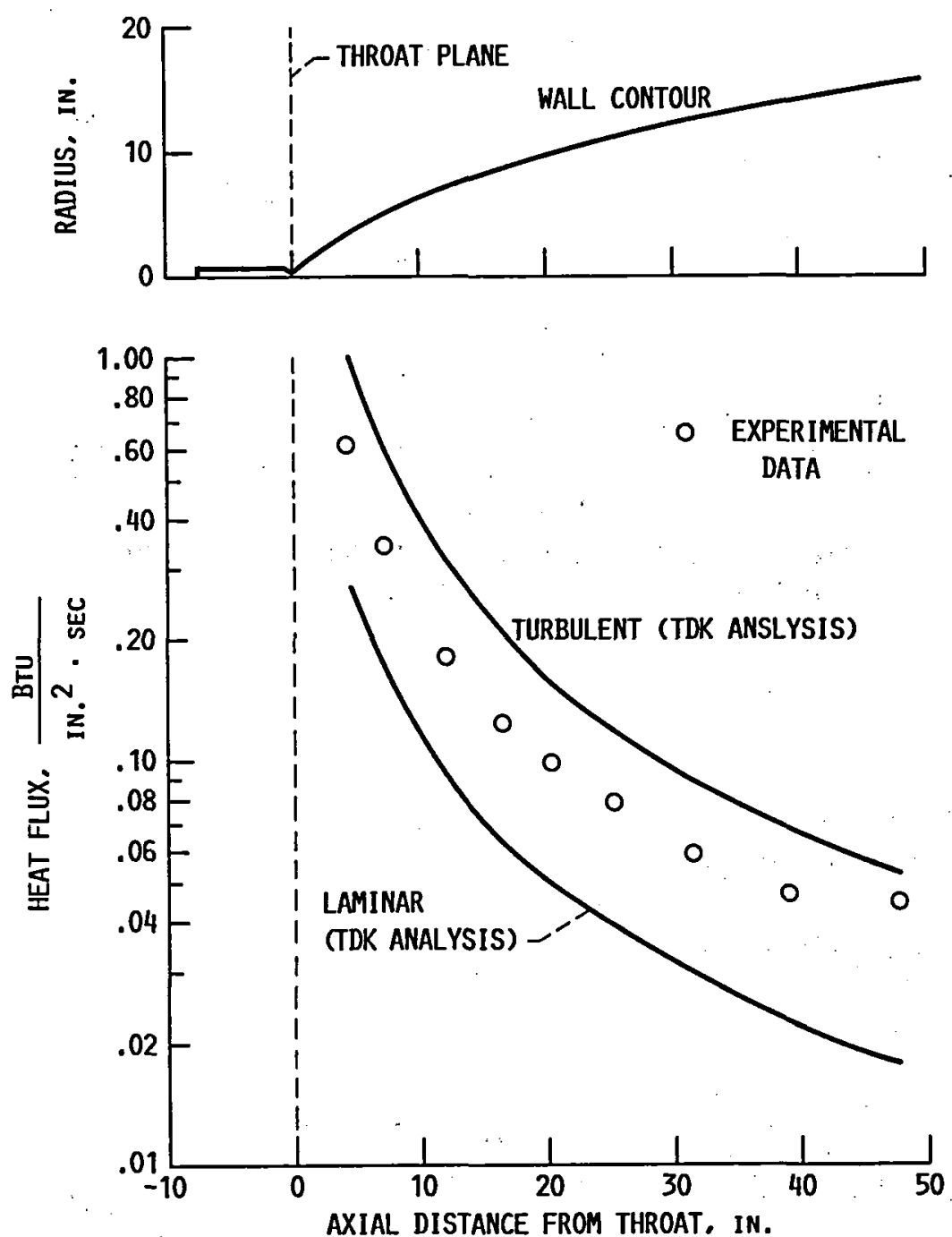

FIGURE 9. - EXPERIMENTAL AND PREDICTED WALL HEAT FLUX AT A CHAMBER PRESSURE OF 1004 PSIA. 


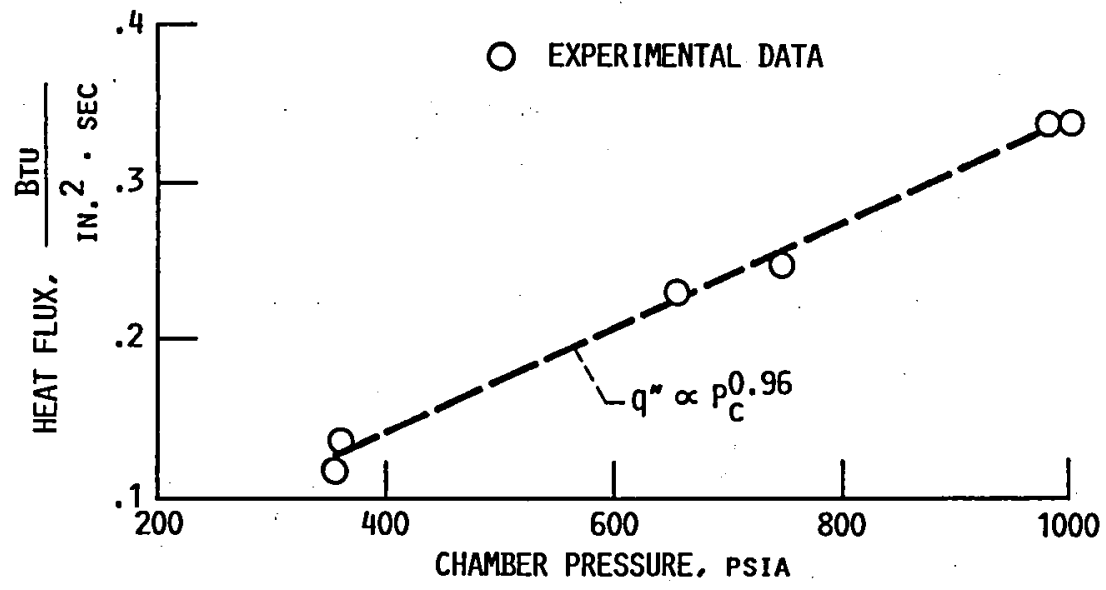

FIGURE 10. - EXPERIMENTAL WALL HEAT FLUX AS A FUNCTION OF CHAMBER PRESSURE AT AN AREA RATIO OF 100 ( $x=7$ IN.).

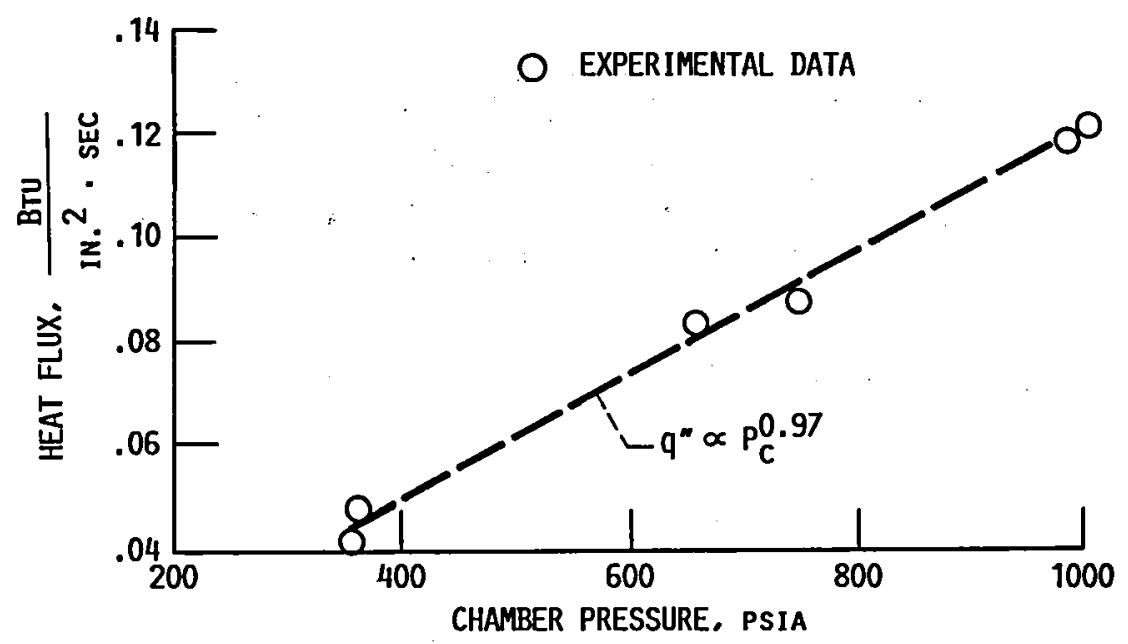

FIGURE 11. - EXPERIMENTAL WALL HEAT FLUX AS A FUNCTION OF CHAMBER PRESSURE AT AN AREA RATIO OF 300 ( $x=16.3$ IN.). 


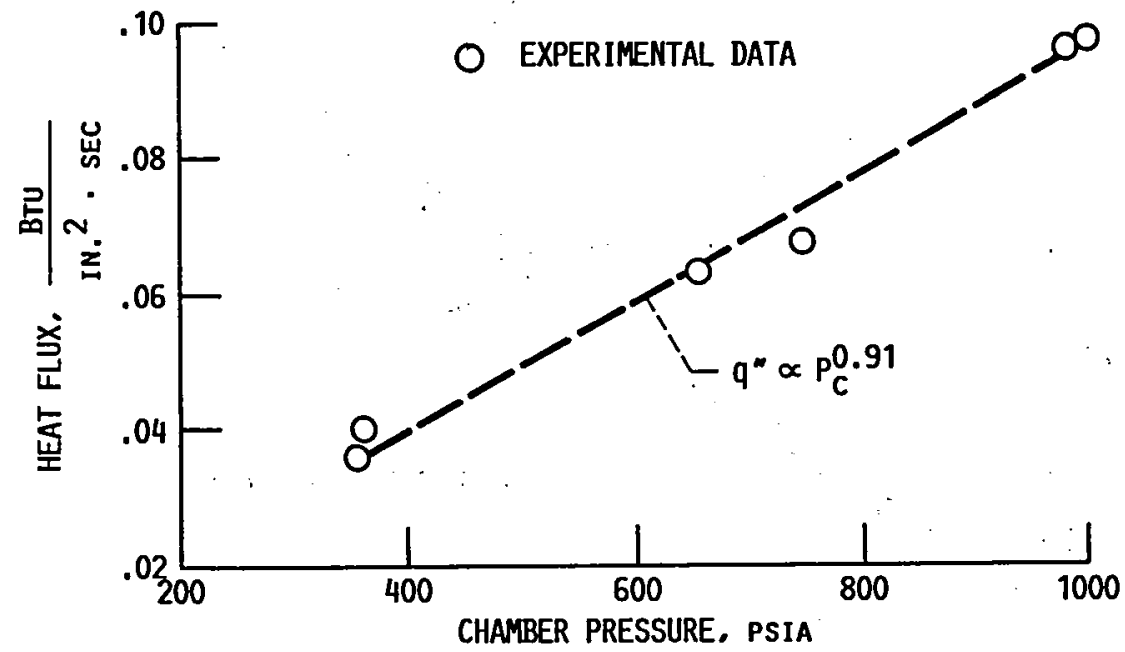

FIGURE 12. - EXPERIMENTAL WALL HEAT FLUX AS A FUNCTION OF CHAMBER PRESSURE AT AN AREA RATIO OF $388(x=20.2$ in.).

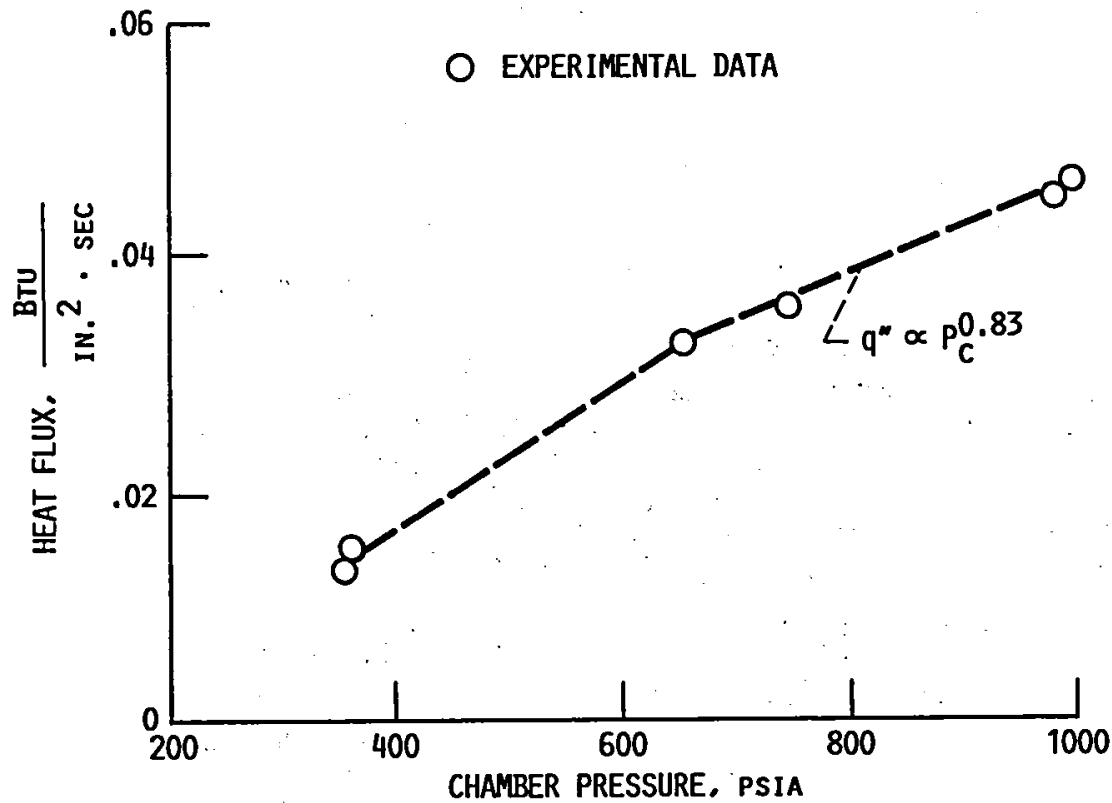

FIGURE 13. - EXPERIMENTAL WALL HEAT FLUX AS A FUNCTION OF CHAMBER PRESSURE AT AN AREA RATIO OF $800(X=39$ IN.). 


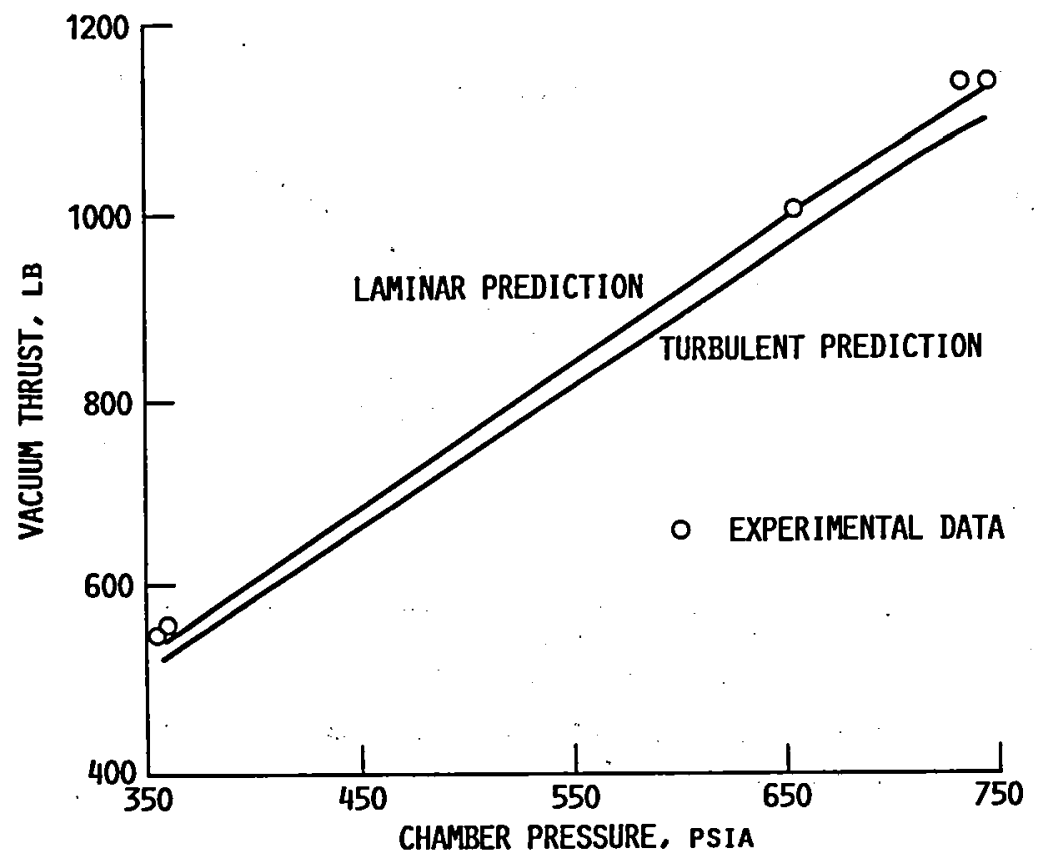

FIGURE 14. - VACUUM THRUST AS A FUNCTION OF CHAMBER PRESSURE.

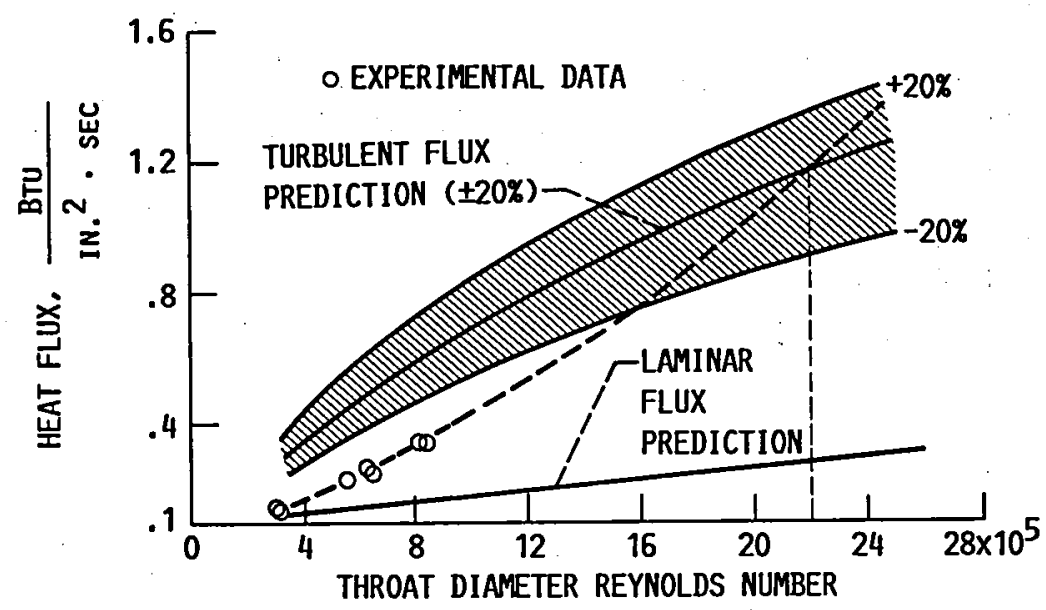

FIGURE 15. - WALL HEAT FLUX AT AN AREA RATIO OF 100 ( $X=7$ IN.). 


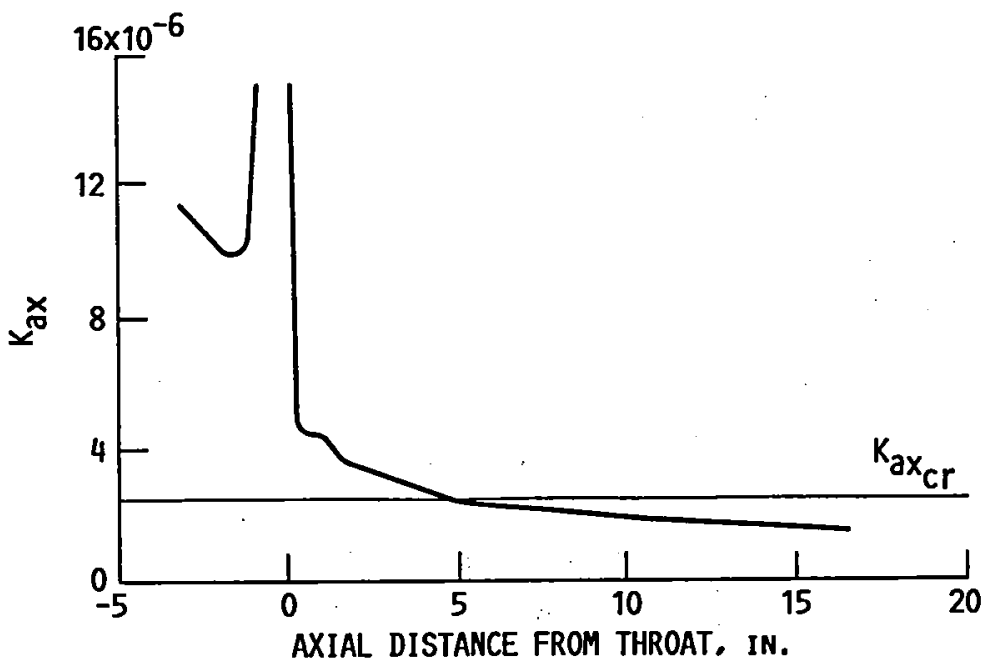

FIGURE 16. - DISTRIBUTION OF $K_{a x}$ AT A CHAMBER PRESSURE OF 360 PSIA.

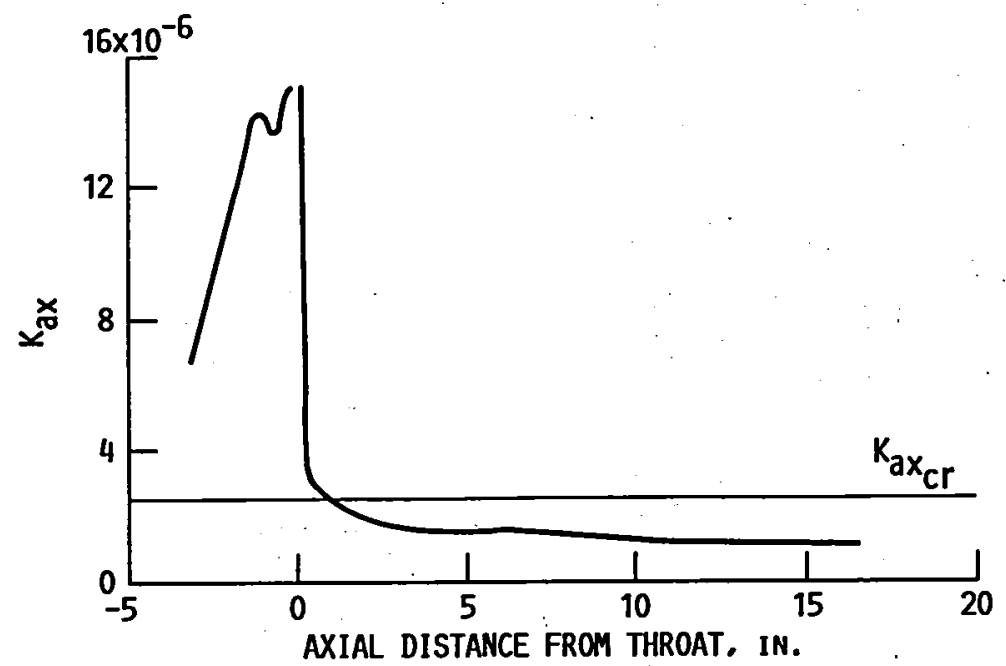

FIGURE 17. - DISTRIBUTION OF $K_{a x}$. AT A CHAMBER PRESSURE OF 656 PSIA. 


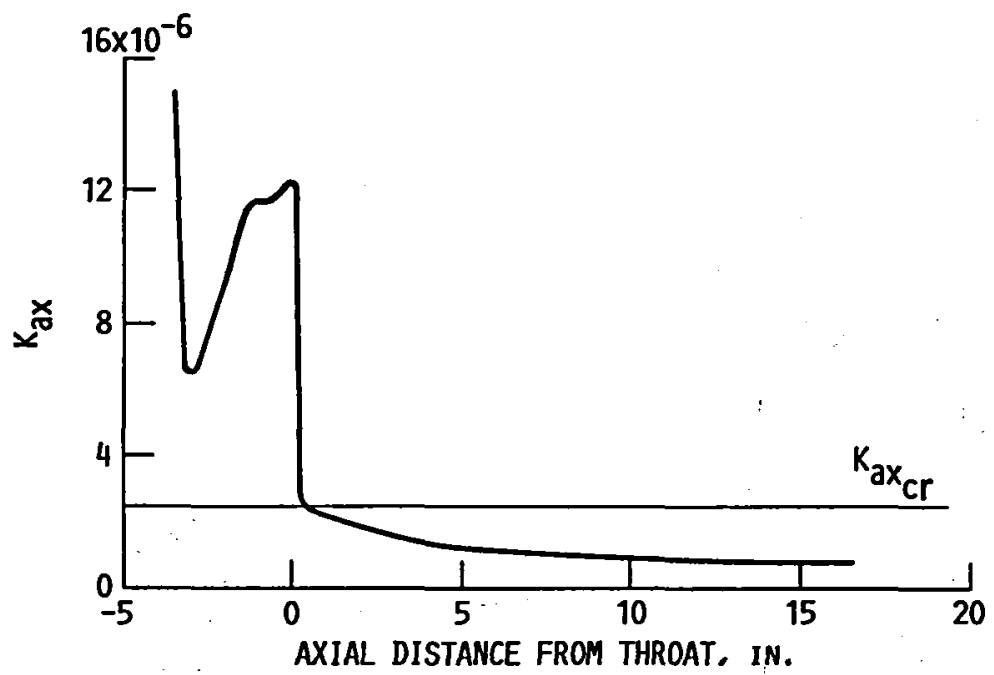

FIGURE 18. - DISTRIBUTION OF $\mathrm{K}_{\mathrm{ax}}$ AT A CHAMBER PRESSURE OF 748 PSIA.

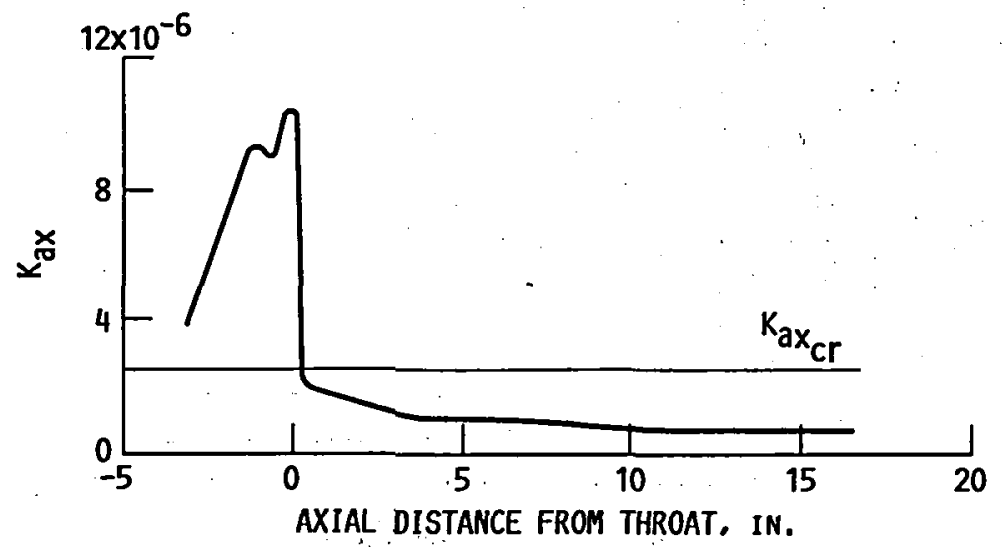
FIGURE 19. - DISTRIBUTION OF $K_{\text {aX }}$ AT A CHAMBER PRES-
SURE OF 984 PSIA. 


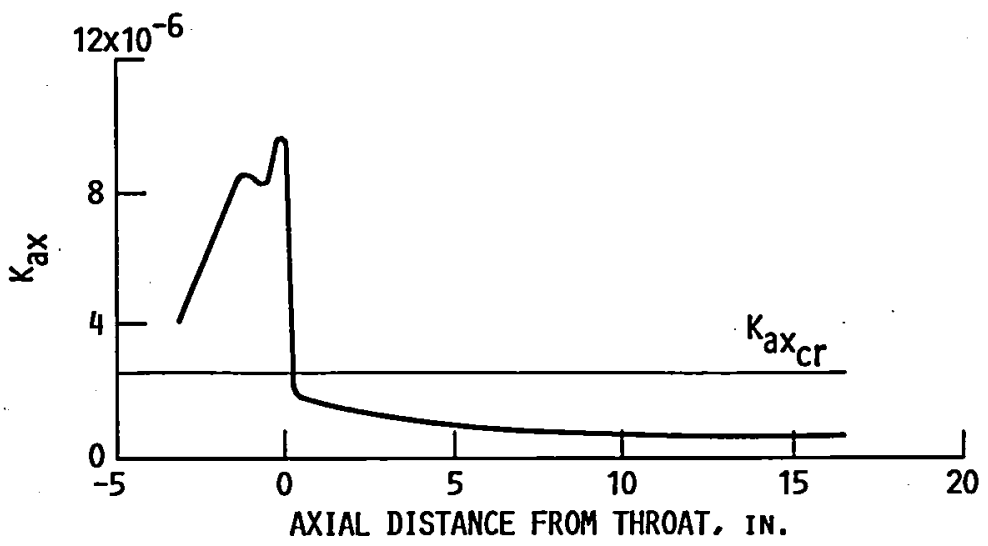

FIGURE 20. - DISTRIBUTION OF $K_{\mathrm{aX}}$ AT A CHAMBER PRESSURE OF 1004 PSIA.

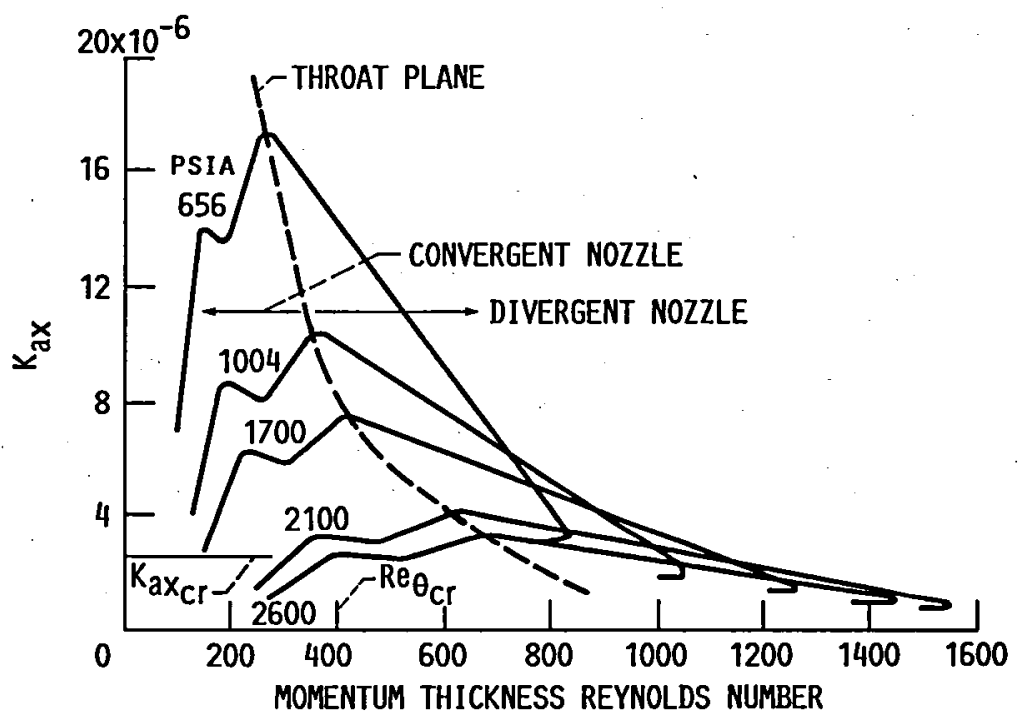

FIGURE 21. - PREDICTED VARIATION OF $K_{\text {aX }}$ AND MOMENTUM THICKNESS REYNOLDS NUMBER ALONG THRUST CHAMBER. 


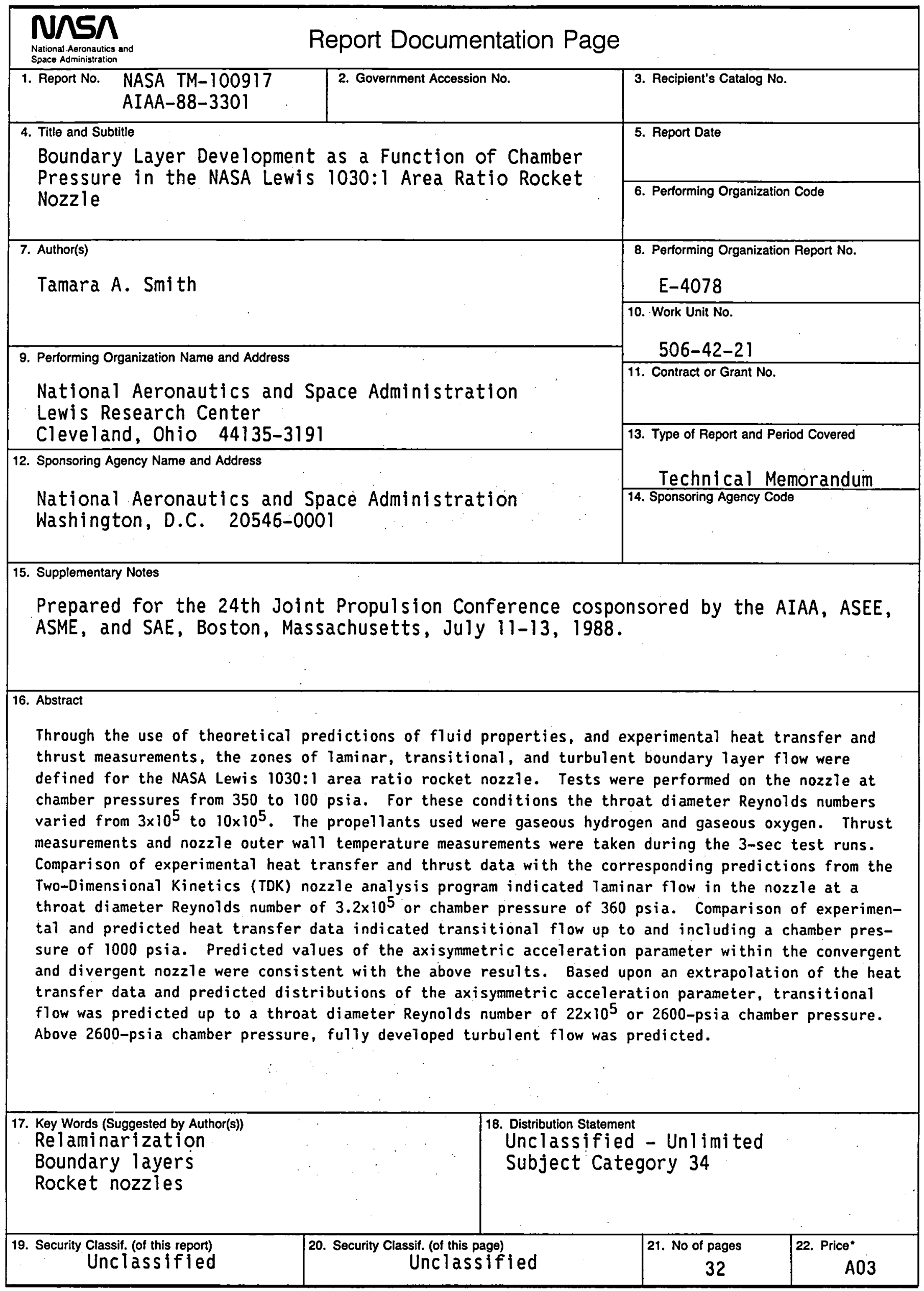


National Aeronautics and Space Administration

Lewis Research Center

Cleveland, Ohio 44135

Ofticial Business

Penalty for Prlvate Use $\$ 300$

\section{ADDRESS CORRECTION REQUESTED}

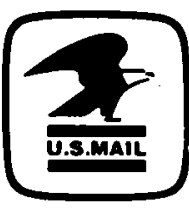

Postage and Fees Paid National Aeronautics and

Space Administratıon NASA.451 